\title{
Effects of a Real Exposure Class XC4 Mediterranean Climate Environment in the Behavior of Mortars Made Using Ternary Binders with Addition of Slag, Fly Ash and Limestone
}

\author{
Javier Ibáñez-Gosálvez ${ }^{1}$, Teresa Real-Herraiz ${ }^{2}$ and José Marcos Ortega ${ }^{1, *}$ \\ 1 Departamento de Ingeniería Civil, Universidad de Alicante, Ap. Correos 99, 03080 Alicante, Spain; \\ javier.ibanez@ua.es \\ 2 Instituto de Matemática Multidisciplinar, Universidad Politécnica de Valencia, Camino de Vera s/n, \\ 46022 Valencia, Spain; tereaher@upv.es \\ * Correspondence: jm.ortega@ua.es; Tel.: +34-96-5903-400 (ext. 2470)
}

Citation: Ibáñez-Gosálvez, J· Real-Herraiz, T.; Ortega, J.M. Effects of a Real Exposure Class XC4 Mediterranean Climate Environment in the Behavior of Mortars Made Using Ternary Binders with Addition of Slag, Fly Ash and Limestone. Materials 2021, 14, 5848. https://doi.org/10.3390/ ma14195848

Academic Editor: Nadezda Stevulova

Received: 20 August 2021 Accepted: 30 September 2021 Published: 6 October 2021

Publisher's Note: MDPI stays neutral with regard to jurisdictional claims in published maps and institutional affiliations.

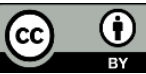

Copyright: (C) 2021 by the authors Licensee MDPI, Basel, Switzerland. This article is an open access article distributed under the terms and conditions of the Creative Commons Attribution (CC BY) license (http://creativecommons.org/licenses /by/4.0/).

\begin{abstract}
For improving the contribution of the cement industry to mitigate global warming, many strategies have been put into practice, such as the use of eco-friendly cements with the incorporation of additions substituting clinker. Nevertheless, the use of ternary binders for the production of commercial cements is still reduced, particularly in Spain. The purpose of this research is to characterize the long-term influence produced by the exposure to a real in situ inland Mediterranean climate condition in the pore network, parameters related to durability and mechanical performance of mortars made with ternary binders, which incorporated limestone, fly ash, and ground granulated blast-furnace slag, in comparison with mortars without additions and binary blended mortars. The site verified the specifications of exposure class XC4 of Eurocode 2. The ternary and binary binders accomplished the prescriptions of cement type CEM II/B. The pore network was studied with mercury intrusion porosimetry and electrical resistivity. Water absorption, diffusion coefficient, carbonation depth, ultrasonic pulse velocity, compressive and flexural strengths have been determined. The exposure to the environment produced after 250 days an increase in porosity, a loss of pore refinement, a rise of the carbonation depths, and a reduction in the mechanical strengths, highlighting the better overall performance of ternary mortar with both fly ash and slag.
\end{abstract}

Keywords: ternary binders; Mediterranean climate environment; real condition exposure; class XC4; fly ash; ground granulated blast-furnace slag; limestone; mechanical properties; microstructure; durability

\section{Introduction}

Nowadays, the cement industry constitutes a very contaminant sector [1,2]. For reducing its greenhouse gases emissions and improve its contribution to mitigating global warming, many strategies have been developed [3-5]. Among them, the use of ecofriendly cements with additions substituting clinker is becoming more and more common [6-8]. Most of these additions or supplementary cementitious materials are obtained from wastes generated in other industries [9-12], so the reuse of these wastes in cement manufacture would avoid other environmental impacts, also contributing to sustainability. In addition, it has been reported that the use of some of these additions produces an enhancement in the behavior of cementitious materials $[10,13,14]$, so the study of their effects still constitutes a relevant area of investigation.

Two of the additions mostly used are fly ash and ground granulated blast-furnace slag. They belong to the group of active additions because they have hydraulic and/or pozzolanic activity $[15,16]$. For fly ash, it is able to react with portlandite $[13,15,17]$ formed 
during the hydration reactions of clinker, giving as a result hydrated phases, which reduce the pore size, entailing a better performance of the material $[10,13]$. The blast-furnace slag is capable of reacting with the water since the setting of the materials, producing the formation of additional calcium-silicate-hydrate ( $\mathrm{CSH}$ ) phases, which leads to a refinement of the pore structure [10-12,18] and an enhancement of durability and mechanical strength $[19,20]$.

There are also additions without the abovementioned pozzolanic or hydraulic activity that are commonly used in cement manufacture as clinker replacement. The most popular of them is limestone. This addition act as filler in cementitious materials, having a positive influence on their pore network, fresh and hardened properties [21-23].

With regard to the manufacture of commercial cements with additions, today, those made with binary binders are mainly produced. In these binary binders, clinker is partially replaced by one addition. However, the standards related to cement production [24] allow the possibility of substituting clinker by more than one addition in the same binder. In the case of ternary binders, in which clinker is in part substituted by two additions, their use in the production of commercial cements is still very low, particularly in Spain. In these ternary binders, incorporating two additions could bring a better performance of cementitious materials due to the possible synergetic effects of their combination [25-28]. Then, to study the behavior of cement-based materials with ternary binders [21,29-31] focused on the use of these binders for commercial cements manufacture would constitute a potential field of investigation for providing more alternatives to cut down the ecological impacts of cement production.

In that regard, the cement-based materials that belong to real construction elements are subject to different environmental conditions depending on their geographical location, which differ from those laboratory conditions in which their behavior is generally studied. It has been reported that the active additions are more sensitive to the variations in the hardening relative humidity and temperature because the variations in these environmental parameters could affect the development of hydration and pozzolanic reactions [32-34]. In this line, several authors [35-40] have studied the behavior of cement-based materials with binary binders exposed to real insitu conditions, obtaining an overall variability depending on the climate of the location in which the samples were sited. Therefore, the study of the performance of cement-based materials prepared with ternary binders exposed to real environments could be relevant for assessing if they are suitable for being used in commercial cements manufacture.

Then, the purpose of this work is to study the long-term influence produced by the exposure to a real in situ inland Mediterranean climate environment in the pore structure, mechanical performance, and durability-related parameters of mortars made with ternary binders, which incorporated the additions of limestone, fly ash and ground granulated blast-furnace slag. This exposure site verified the specifications of exposure class XC4, according to Eurocode 2 [41]. The reason for choosing the abovementioned additions was because they are mostly used in the manufacture of blended commercial cements in Spain. Furthermore, for making easier the real application of the obtained results by cement producers, the analyzed ternary binders accomplished the prescriptions for a normalized commercial cement type CEM II/B-M, defined by the Spanish and European standard UNE-EN 197-1 [24]. The performance of mortars prepared using ternary binders has been compared to that noted for mortars taken as reference, made with ordinary Portland cement without additions, as well as with other mortars prepared using binary binders, that included one of the analyzed additions as clinker substitution. 


\section{Materials and Methods}

\subsection{Materials and Sample Preparation}

Mortars made with different binders were studied. The first type of mortar was the reference one, which was prepared using an ordinary Portland cement without additions CEM I 42.5 R (Spanish and European standard UNE-EN 197-1 [24]). The designation of this reference mortar was REF in the description and discussion of results.

Furthermore, mortars made with three different binary binders were also analyzed. In these binders, 30\% of the cement CEM I $42.5 \mathrm{R}$ was substituted by limestone, fly ash, and ground granulated blast-furnace slag, and they were, respectively, named as L, F, and $S$ in the presentation of results.

Three ternary binders were also prepared. One of these binders included $15 \%$ slag and $15 \%$ limestone as cement CEM I $42.5 \mathrm{R}$ replacement, and its designation was SL. Another ternary binder consisted of substituting the previously mentioned cement CEM I $42.5 \mathrm{R}$ by $15 \%$ slag and $15 \%$ fly ash, and it was named SF. Finally, in the last of these ternary binders, whose designation was FL, the cement CEM I $42.5 \mathrm{R}$ was partially replaced by $15 \%$ fly ash and $15 \%$ limestone additions. In Table 1 are shown the abovementioned designations of the binders studied and their meaning.

Table 1. Designation of the mortars studied and percentage (in weight) of CEM I and additions [42].

\begin{tabular}{ccccc}
\hline Designation & CEM I 42.5 R & Limestone & Blast-Furnace Slag & Fly Ash \\
\hline REF & $100 \%$ & - & - & - \\
L & $70 \%$ & $30 \%$ & - & - \\
S & $70 \%$ & - & $30 \%$ & - \\
F & $70 \%$ & - & - & $30 \%$ \\
SL & $70 \%$ & $15 \%$ & $15 \%$ & - \\
SF & $70 \%$ & - & $15 \%$ & $15 \%$ \\
FL & $70 \%$ & $15 \%$ & - & $15 \%$ \\
\hline
\end{tabular}

Limestone, ground granulated blast-furnace slag, and fly ash accomplished the specifications of the UNE-EN 197-1 standard [24] for being used as additions in the manufacture of commercial cements. The three additions studied in this research were provided by the company Cementos Portland Valderrivas (Madrid, Spain), and they are used at this time in the commercial blended cements produced by this company. The chemical compositions of these additions are gathered in Table 2.

Table 2. Chemical components of limestone, fly ash, and blast-furnace slag.

\begin{tabular}{cccc}
\hline Components & Blast-Furnace Slag & Fly Ash & Limestone \\
\hline $\mathrm{MgO}$ & $6.98 \%$ & $1.40 \%$ & $0.47 \%$ \\
$\mathrm{Al}_{2} \mathrm{O}_{3}$ & $10.10 \%$ & $27.70 \%$ & $1.22 \%$ \\
$\mathrm{SiO}_{2}$ & $31.50 \%$ & $54.40 \%$ & $2.85 \%$ \\
$\mathrm{SO}_{3}$ & $1.94 \%$ & $0.53 \%$ & $0.10 \%$ \\
$\mathrm{~K}$ & $0.52 \%$ & $3.12 \%$ & $0.18 \%$ \\
$\mathrm{CaO}$ & $46.80 \%$ & $2.55 \%$ & $94.40 \%$ \\
$\mathrm{TiO}_{2}$ & $0.94 \%$ & $1.05 \%$ & $0.11 \%$ \\
$\mathrm{MnO} \mathrm{Fe}$ & $0.17 \%$ & $0.06 \%$ & - \\
$\mathrm{P}_{2} \mathrm{O}$ & $0.37 \%$ & $0.06 \%$ & $0.54 \%$ \\
$\mathrm{Na}$ & $0.02 \%$ & $0.46 \%$ & $0.02 \%$ \\
$\mathrm{ZnO}$ & $0.30 \%$ & - & - \\
\hline
\end{tabular}


The studied binders verified the prescriptions for a standardized commercial cement type CEM II/B, defined by the standard UNE-EN 197-1 [24]. The motivation for selecting this kind of cement is due to the fact that at present, cement type II [24] is mostly manufactured in Spain, then this may make easier a broader potential real application of the results achieved in this work.

The water to binder ratio was 0.5 for all the series of mortars. The samples were made with an aggregate to binder ratio of 3:1, and the fine aggregate used accomplished the specifications of the standard UNE-EN 196-1 [43].

Three kinds of samples were set. The first was prismatic samples with sizes $4 \times 4 \times 16$ $\mathrm{cm}^{3}$. The second type of specimen was cylinders with dimensions $6 \mathrm{~cm}$ height and $5 \mathrm{~cm}$ diameter. Lastly, another kind of cylindrical sample was made, in this case with $10 \mathrm{~cm}$ diameter and $22 \mathrm{~cm}$ height.

All the samples were stored in a chamber under an optimum laboratory condition $\left(20{ }^{\circ} \mathrm{C}\right.$ temperature and $95 \%$ relative humidity) during the first $24 \mathrm{~h}$ after setting. Once ended this time, they were de-molded, and they were cured under that optimum condition up to 7 hardening days when they were moved to the real in situ exposure site. Several experimental works have shown $[34,35,44]$ the significance of curing in the development of properties of cement-based materials exposed to non-optimum environments. For that, here has been chosen a curing period of 7 days. Finally, the tests were conducted at 28 and 250 days.

\subsection{Environmental Exposure Condition}

The real in situ condition consisted of exposing the samples to a Mediterranean climate environment in an inland location sited in Orxeta town $\left(38^{\circ} 33^{\prime} 47^{\prime \prime} \mathrm{N}, 0^{\circ} 15^{\prime} 43^{\prime \prime} \mathrm{W}\right.$, 177 m.a.s.l.), which belongs to Alicante province (Spain) (see Figure 1). This exposure station was not too far away from the coast $(10 \mathrm{~km}$ approximately). The samples were placed on the roof of a detached house, and they were not protected from the weather conditions. This location would accomplish the specifications of exposure class XC4 (corrosion induced by carbonation, cyclic wet and dry) defined by the Eurocode 2 [41].

The exposure period studied in this work started at the age of 7 hardening days, once finished the curing time of the samples, as has been explained in the previous subsection, and finished at 250 hardening days, covering the months from February to October. During this period, the relative humidity and temperature in the exposure site were registered each hour. The evolution of temperature and relative humidity measured in the exposure station along the studied time interval is shown in Figures 2 and 3, respectively. Moreover, in Figure 4 it is represented the absolute maximum, the absolute minimum, and the variation interval of the daily average environmental relative humidity and temperature at which the specimens tested at 28 and 250 days were exposed. On the other hand, rain is another environmental factor that may have an influence on the water saturation degree of the specimens, and as a consequence, in the development of their properties and pore network. The daily rainfall registered in the location along the exposure period is represented in Figure 5 .

As can be seen, in general, both temperature and relative humidity showed high variability. With regard to the time period until 28 hardening days, it corresponded to the final of the winter season in the exposure site. The temperatures registered in that period were overall mild, ranging the daily average temperature between 12 and $18{ }^{\circ} \mathrm{C}$, with an absolute maximum value of $23{ }^{\circ} \mathrm{C}$ (see Figure 4). In addition, along this period, it was several rainy days (see Figure 5), which produced that the environmental relative humidity registered was relatively high, particularly from 18 to 28 days (see Figure 3), with an absolute maximum value near $100 \%$ (see Figure 4).

With respect to the period between 28 and 250 hardening days, it covered the spring and the summer seasons and the initial part of the autumn. As has been expected, in this period, it has been registered higher daily average temperatures, reaching an absolute maximum value of $35{ }^{\circ} \mathrm{C}$ (see Figure 4). The relative humidity showed oscillations, 
alternating periods with moderately high and low values, although there were several days in which it was registered a relative humidity lower than $50 \%$ (see Figure 3), with an absolute minimum value around 10\% (see Figure 4). Finally, scarce rainfall has been registered during this period (see Figure 5).



Figure 1. Location of the exposure site (black line squares). The specimens were placed on the roof of a detached house located in Orxeta town (Alicante province, Spain), and they were not protected from the weather conditions. The satellite images were obtained using the Google Earth software (Version 7.3.4, Mountain View, CA, USA). 


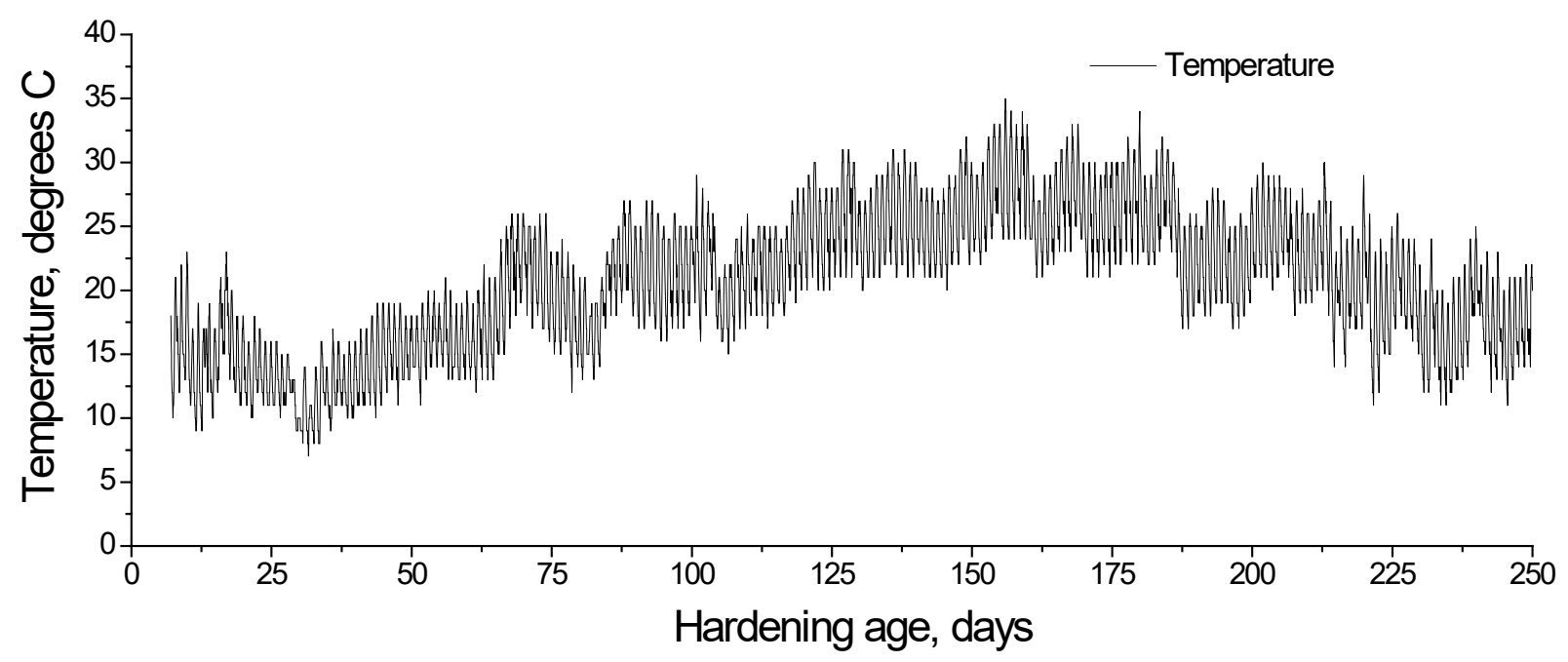

Figure 2. Temperature registered in the exposure station along the time period studied.

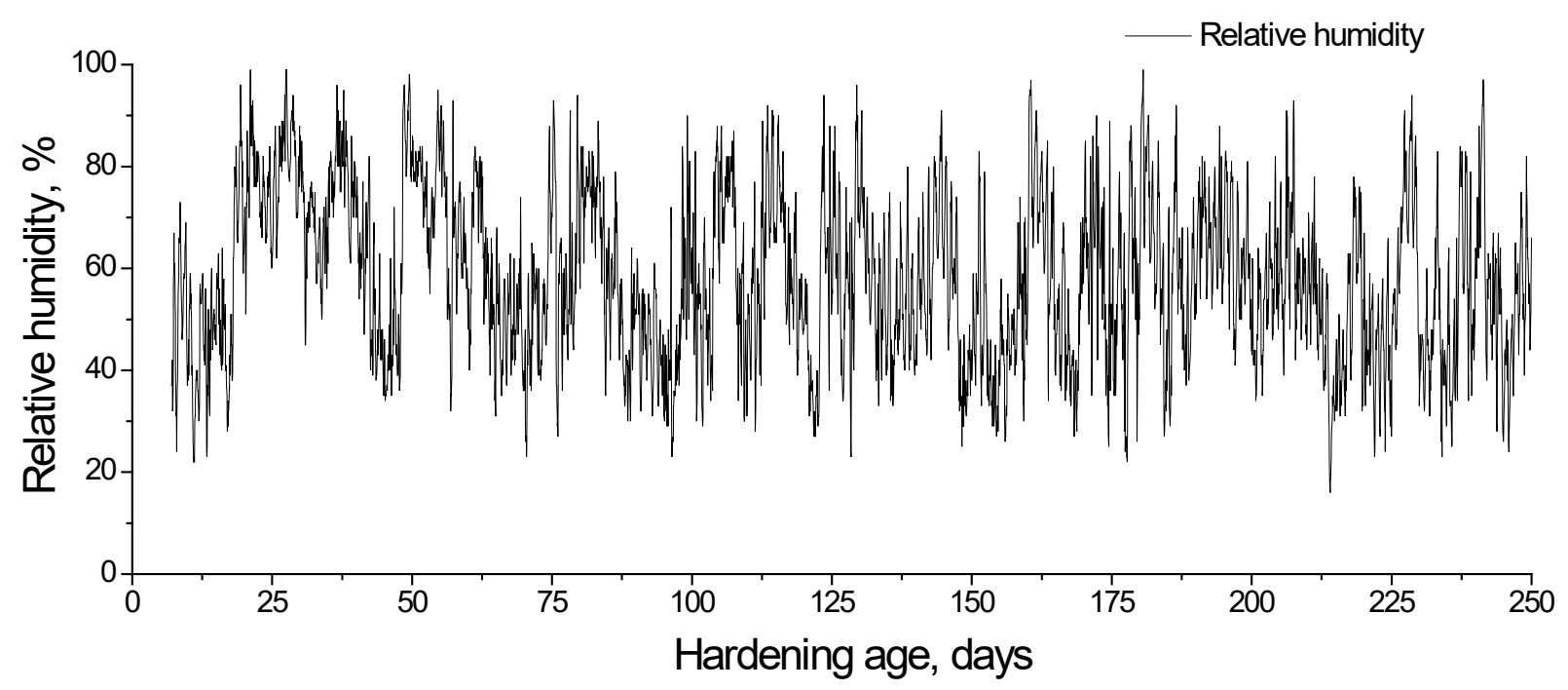

Figure 3. Relative humidity registered in the exposure station along the time period studied.

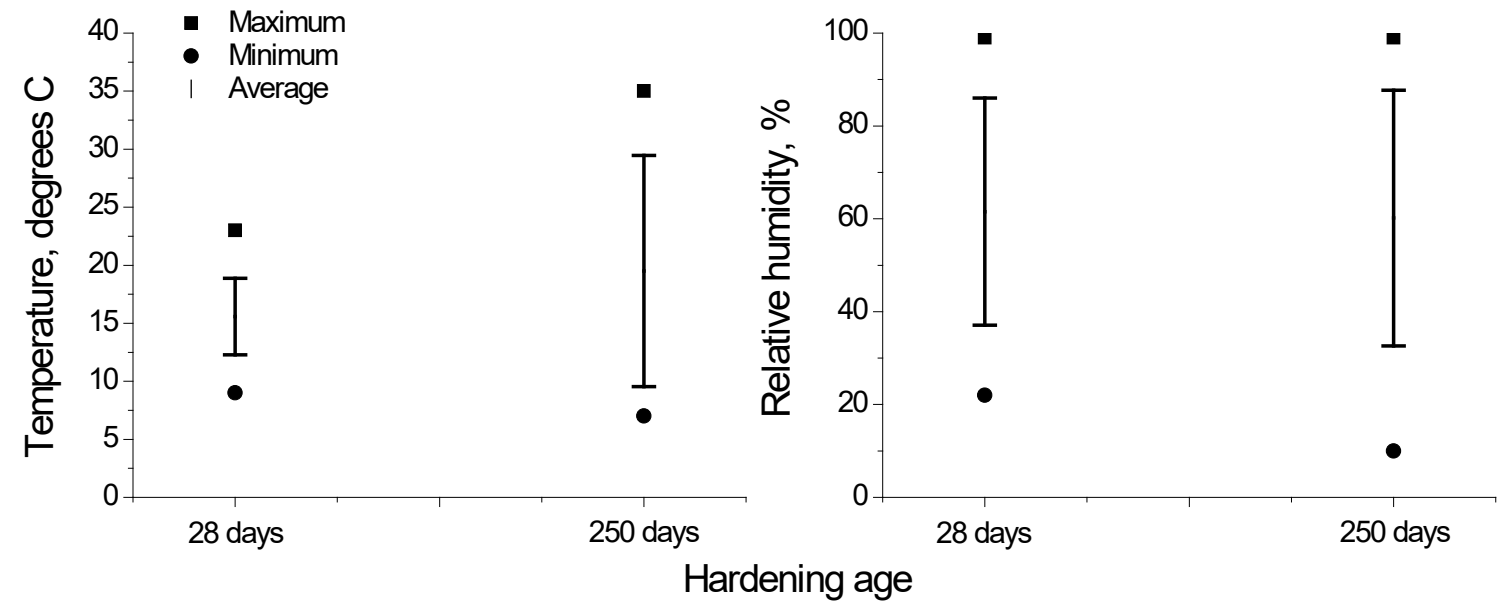

Figure 4. Absolute maximum, absolute minimum, and variation interval of the average daily temperature and relative humidity at which the samples tested at 28 and 250 days were exposed. 


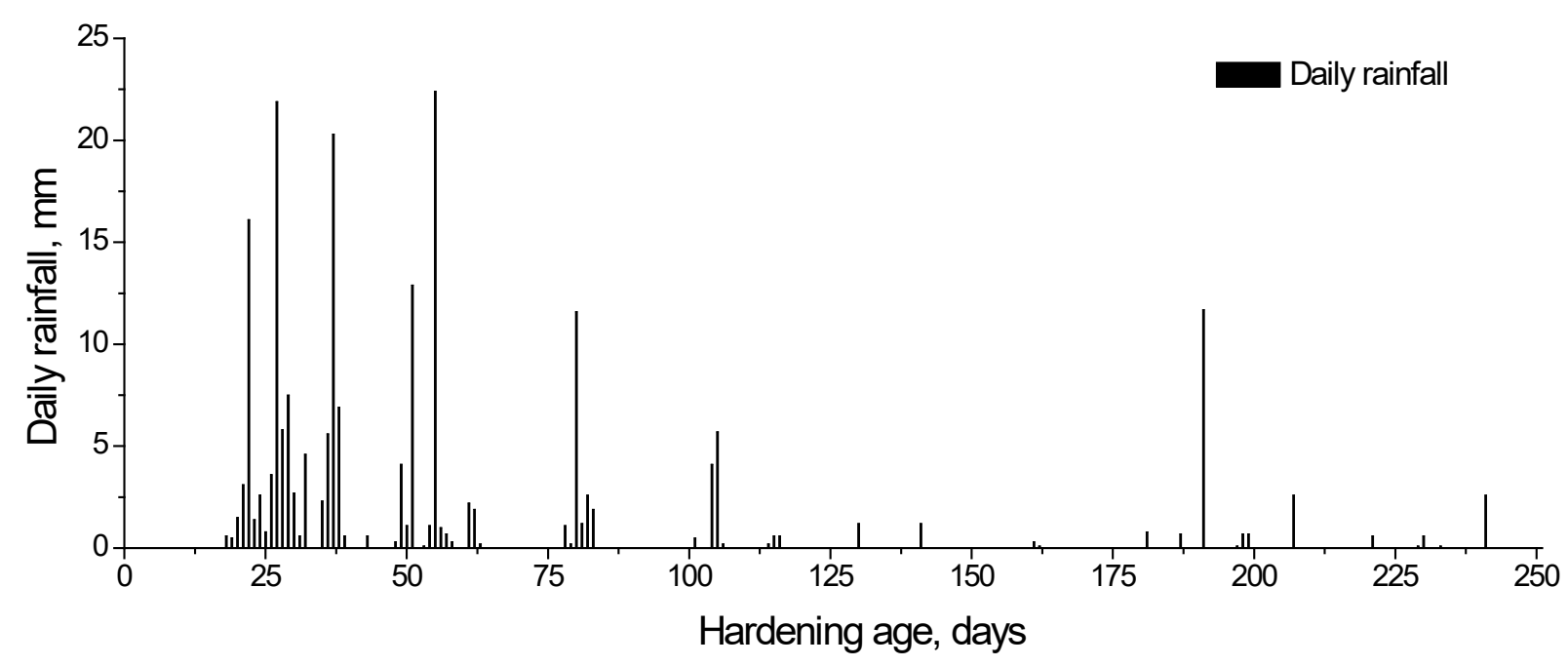

Figure 5. Daily rainfall registered in the station over the exposure period.

\subsection{Mercury Intrusion Porosimetry}

The mercury intrusion porosimetry technique allows getting information on the pore structure of materials [45-47]. In this work, the porosimeter used for performing this technique was a Poremaster-60 GT model of Quantachrome Instruments (Boynton Beach, FL, USA). The tested samples were dried in an oven at $50^{\circ} \mathrm{C}$ for $48 \mathrm{~h}$ before the porosimetry test. In this work, the total porosity and the pore size distributions determined with this technique were analyzed. For the pore size distributions, it was considered the following pore size ranges: $<10 \mathrm{~nm}, 10-100 \mathrm{~nm}, 100 \mathrm{~nm}$ to $1 \mu \mathrm{m}, 1-10 \mu \mathrm{m}$, $10 \mu \mathrm{m}$ to $0.1 \mathrm{~mm}$, and $>0.1 \mathrm{~mm}[48,49]$. Two measurements were made on each binder at the corresponding testing ages. Pieces taken from cylindrical specimens with $6 \mathrm{~cm}$ height and $5 \mathrm{~cm}$ diameter were tested.

\subsection{Electrical Resistivity}

The electrical resistivity allows getting information about to microstructure and connectivity of the pores in cementitious materials [50,51]. Here, the resistivity of the mortars was determined using the non-destructive Wenner four-point test, following the prescriptions of the Spanish standard UNE 83988-2 [52]. This electrical resistivity was directly measured with a Torrent permeability tester (Proceq, Schwerzenbach, Zurich, Switzerland) on cylinders with $10 \mathrm{~cm}$ diameter and $22 \mathrm{~cm}$ height several times until 250 days. Before each measurement, the surface of the cylinders was prepared according to technical recommendation number 5 of Alconpat International [53]. Three cylinders were tested for each mortar type, and four measurements were performed per specimen at each testing age.

\subsection{Water Absorption}

The absorption after immersion was obtained according to the procedure included in the ASTM Standard C642-06 [54]. Six pieces taken from cylinders with dimensions $6 \mathrm{~cm}$ height and $5 \mathrm{~cm}$ diameter were tested for each mortar type at 28 and 250 days.

\subsection{Steady-State Chloride Diffusion Coefficient}

The steady-state chloride diffusion coefficient has been obtained from the electrical resistivity of the samples saturated with water. The electrical resistivity was determined following the procedure described in Section 2.4. Specimens were water-saturated for 24 $\mathrm{h}$ following the standard ASTM C1202-97 [55]. Three cylinders with $10 \mathrm{~cm}$ diameter and 
$22 \mathrm{~cm}$ height were tested at 28 and 250 days for each binder. Four measurements were performed per specimen at both testing ages. Lastly, the steady-state diffusion coefficient was calculated with the next expression [56]:

$$
\mathrm{D}_{\mathrm{S}}=\frac{2 \times 10^{-10}}{\rho}
$$

where $D_{s}$ is the chloride steady-state diffusion coefficient through the sample $\left(\mathrm{m}^{2} / \mathrm{s}\right)$ and $\rho$ is the electrical resistivity of the specimen $(\Omega \cdot m)$.

\subsection{Carbonation Depth}

The evolution of carbonation depth in the analyzed mortars was determined in accordance with RILEM (International Union of Laboratories and Experts in Construction Materials, Systems and Structures) recommendation CPC-18 [57]. Pieces obtained from the original cylindrical specimens with $6 \mathrm{~cm}$ height and $5 \mathrm{~cm}$ diameter were sprayed with a $1 \%$ phenolphthalein solution. The depth of the colorless carbonated part from the external surface of the sample was measured. For each binder, six pieces taken from the cylindrical specimens previously indicated were tested at 28 and 250 hardening days.

\subsection{Mechanical Strengths}

The compressive and flexural strengths were obtained following the prescriptions of the Spanish and European standard UNE-EN 1015-11 [58]. For each binder, three different prismatic samples with dimensions $4 \times 4 \times 16 \mathrm{~cm}^{3}$ were tested at 28 and 250 hardening days.

\subsection{Ultrasonic Pulse Velocity}

The ultrasonic pulse velocity (UPV) provides information about the mechanical performance of the material. This parameter was obtained following the procedure explained in the standard UNE-EN 12504-4 [59]. In this test, the propagation time of the ultrasonic waves in the largest dimension of the sample $(160 \mathrm{~mm})$ was measured with direct transmission, using a Pundit Lab model of Proceq manufacturer (Schwerzenbach, Zurich, Switzerland). Contact transducers that emitted ultrasonic pulses at $54 \mathrm{kHz}$ were attached to the square sides of the samples with a coupling agent. The UPV was determined from the propagation time and the length of the sample. This parameter was obtained at several ages until 250 days. At each age, for the same binder, three prismatic specimens with dimensions $4 \times 4 \times 16 \mathrm{~cm}^{3}$ were tested, and three determinations were performed on each specimen.

\section{Results}

\subsection{Mercury Intrusion Porosimetry}

Regarding the results of mercury intrusion porosimetry, the evolution of total porosity is shown in Figure 6. At 28 days, the smallest values of this porosity were noted for REF, S, F, SL, and SF series, with scarce differences among them. On the other hand, the highest total porosity was observed for L mortars, followed by FL ones. Between 28 and 250 days, it has been noted an increase in this parameter for all the mortars. This rise was more noticeable for the REF and SF series. At 250 days, $S$ and F series showed the lowest total porosity values, followed by SL mortars, being higher than the porosity obtained for the REF, SF, and FL series. Lastly, the highest value of this porosity after 250 hardening days was obtained for L mortars. 


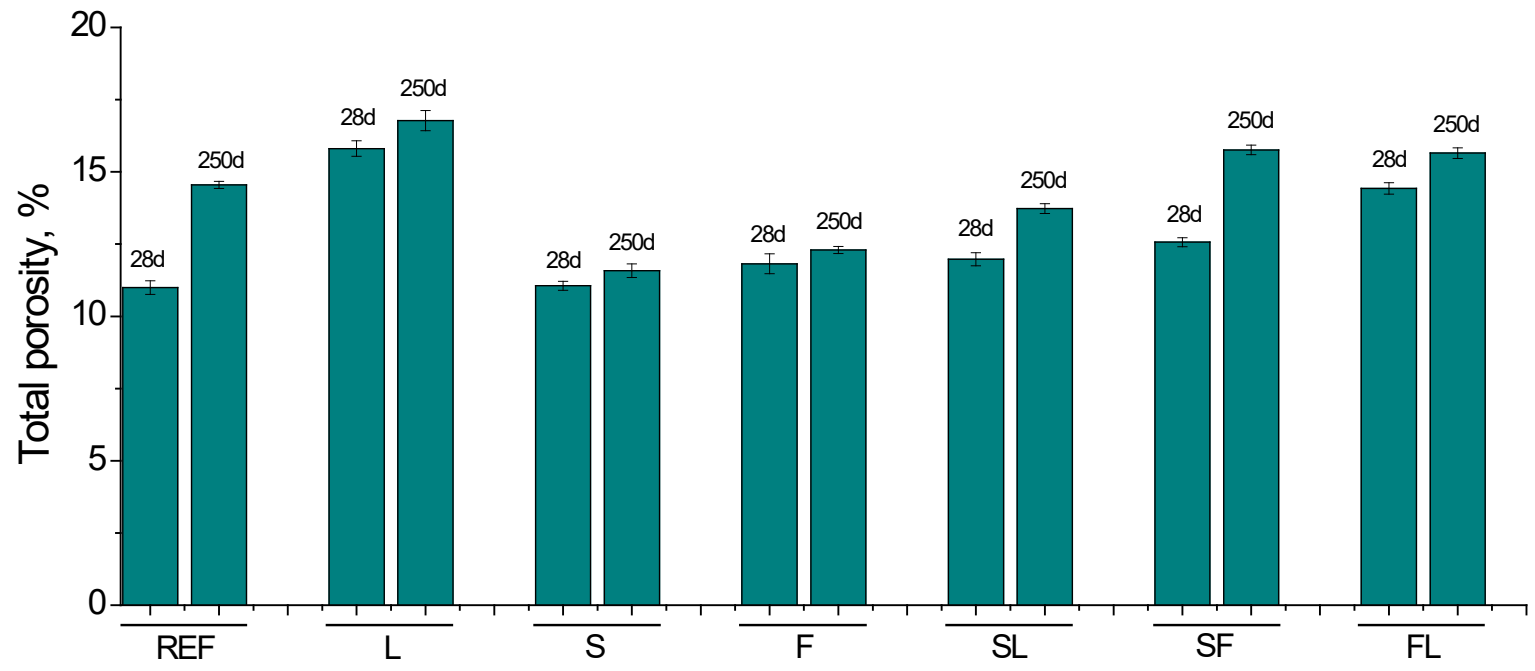

Figure 6. Results of total porosity for the analyzed binders. In this figure and in the next figures, the mean value of the parameter obtained for each binder is represented. In addition, the error bars represent the standard deviation.

In relation to the pore size distributions, they are depicted in Figure 7. After 28 days, the percentage of pores with diameters smaller than $100 \mathrm{~nm}$ (ranges 10-100 nm and <10 $\mathrm{nm}$ ) was relatively similar for REF, S, F, and SF mortars, showing SF ones the highest relative volume of pores in the interval $<10 \mathrm{~nm}$. Regarding the other ternary binders (SL and FL series), the percentage of pores lower than $100 \mathrm{~nm}$ at 28 days was slightly lower compared to the abovementioned series. Between 28 and 250 days, all the analyzed binders showed a noticeable reduction in the percentage of finer pores. At the last age studied, the relative volume of pores with diameters lower than $100 \mathrm{~nm}$ was greater for $\mathrm{F}$ and SF series in comparison with other binders. At 28 and 250 days ages studied, the lowest percentage of finer pores was observed for L mortars.

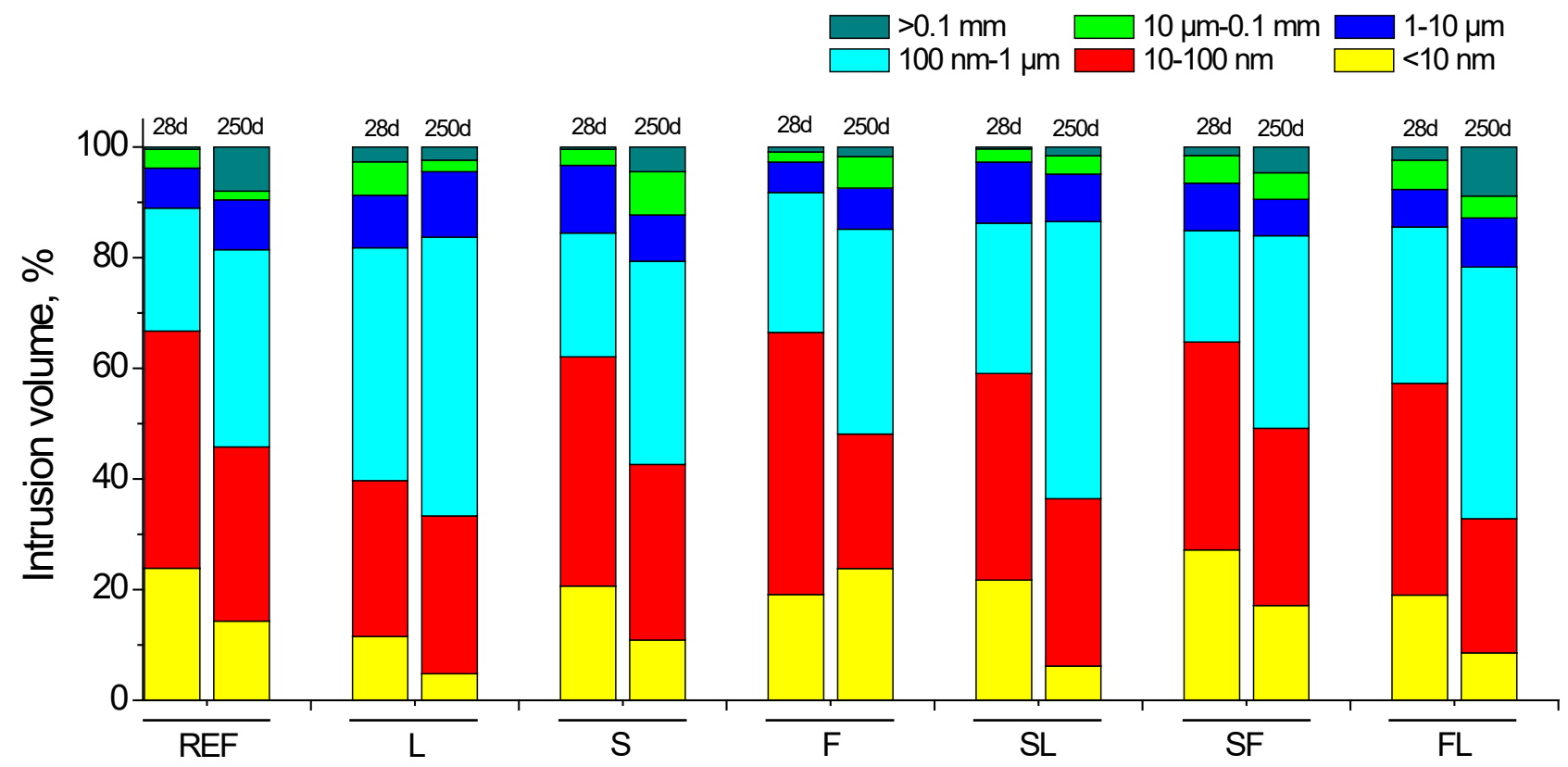

Figure 7. Pore size distributions obtained for the studied mortars. 


\subsection{Electrical Resistivity}

The electrical resistivity results can be observed in Figure 8. In the short term, the binary and ternary binders that incorporated slag (S, SL, and SF series) showed higher values of this parameter, particularly $S$ mortars. Since 60 days approximately, mortars made with the binary binder with fly ash (F series) started a noticeable growth of their electrical resistivity, presenting the highest values of this parameter at 250 days. For the ternary mortars with both limestone and fly ash additions (FL series), the tendency was similar, although the more notable increase in electrical resistivity started later. In the long term, the greatest values of the resistivity were noted for mortars with fly ash (F series followed by FL and SF binders), being lower for the other mortars with slag (S and SL series). Finally, REF and L mortars overall showed the lowest electrical resistivity at later ages.

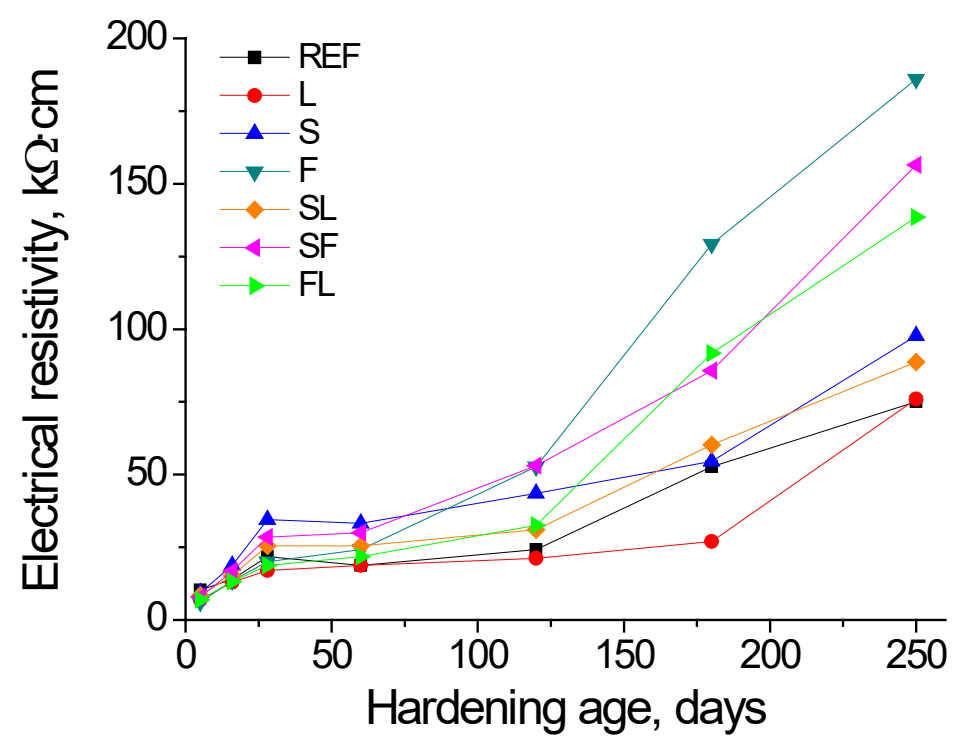

Figure 8. Electrical resistivity results noted for the analyzed mortars.

\subsection{Water Absorption}

The results of water absorption after immersion are represented in Figure 9. This absorption was slightly lower for S, F, and SF series in comparison with the other analyzed binders. In general, small reductions inthe time of absorption after immersion have been noted for all the studied binders. After 250 days, it was scarce higher for binary and ternary binders with limestone addition (L, SL, and FL series). 


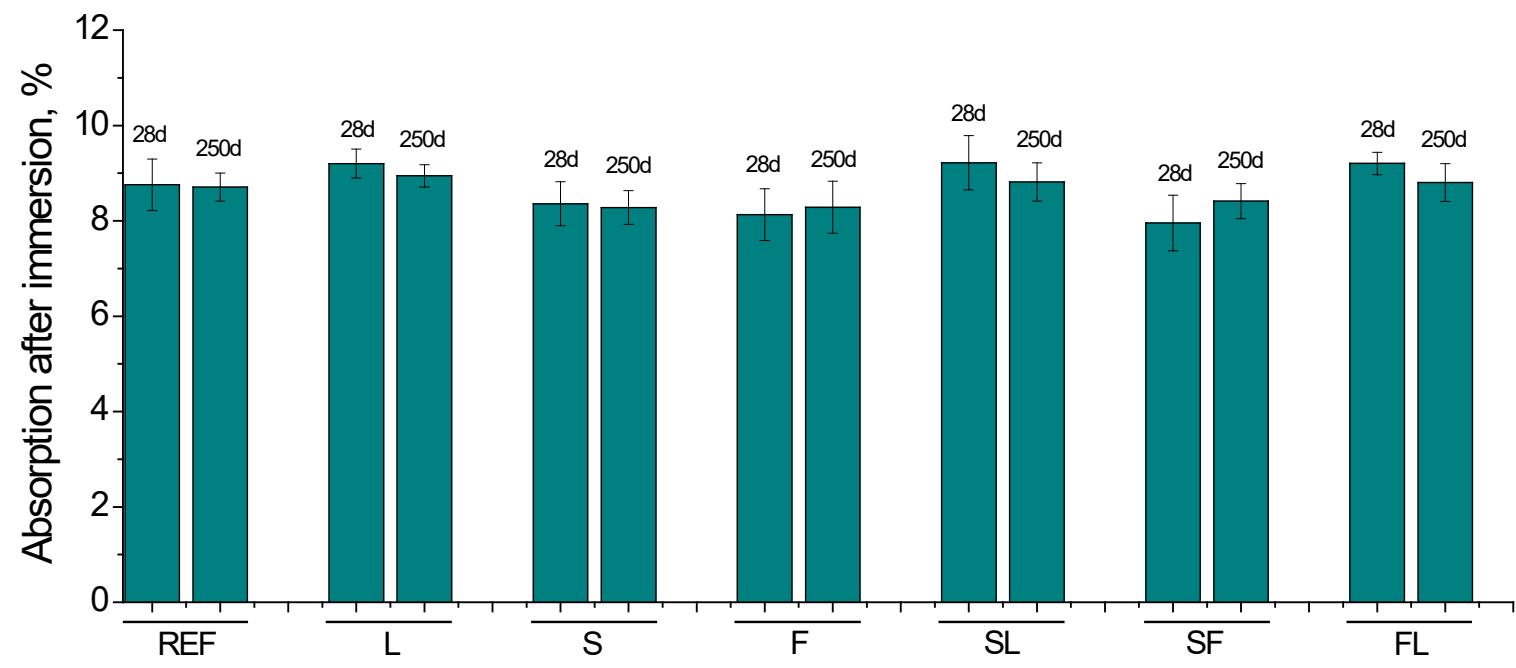

Figure 9. Results of absorption after immersion for the studied binders.

\subsection{Steady-State Chloride Diffusion Coefficient}

The results of the steady-state chloride diffusion coefficient obtained from the saturated sample's resistivity are shown in Figure 10. At 28 days, this coefficient was lower for REF mortars and for specimens prepared with binary and ternary binders with slag (S, SL, and SF series), compared to the other binders with fly ash and limestone (F, FL, and L mortars). Between 28 and 250 days, the diffusion coefficient showed a decrease for mortars that incorporate fly ash and slag (S, F, SL, SF, and FL series), being more noticeable the reduction in this parameter for specimens with fly ash in the binder (F, SF and FL series). For REF and L mortars, the diffusion coefficient hardly decreased between 28 and 250 days. At that last age studied, the smallest coefficients were noted for SF and F specimens, nearly followed by $S$ and FL ones. On the other hand, the diffusion coefficient was scarce greater for SL and REF series at 250 days in comparison with the abovementioned series, while the greatest value of this coefficient at that age was noted for the L series.

$\square$ Diffusion coef.

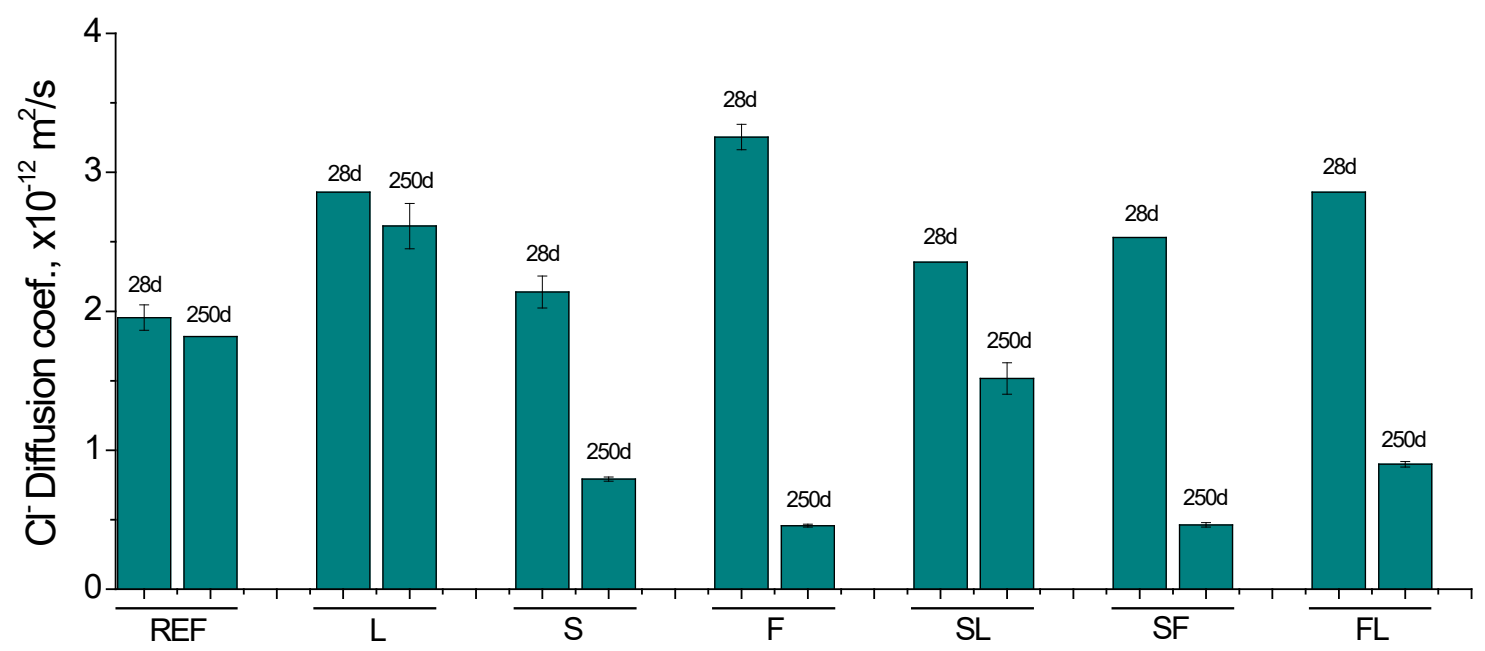

Figure 10. Results of steady-state chloride diffusion coefficient obtained from resistivity of water-saturated samples. 


\subsection{Carbonation Front Depth}

The results of carbonation front depth measurements can be observed in Figure 11. In general, there were no excessive differences in this parameter comparing the different mortars tested. At 28 days, the carbonation depths were lower for REF, S, and SF mortars, with relatively similar values between them. On the other hand, the depths were also similar at that age for L, F, SL, and FL mortars, although they showed higher values compared to the abovementioned series. From 28 to 250 days, the carbonation front depth rose for all the analyzed series. At 250 days, the highest depths were observed for $\mathrm{F}$ and FL mortars. On the other hand, ternary binders with slag (SL and SF) showed at that age very similar carbonation depths to REF specimens.

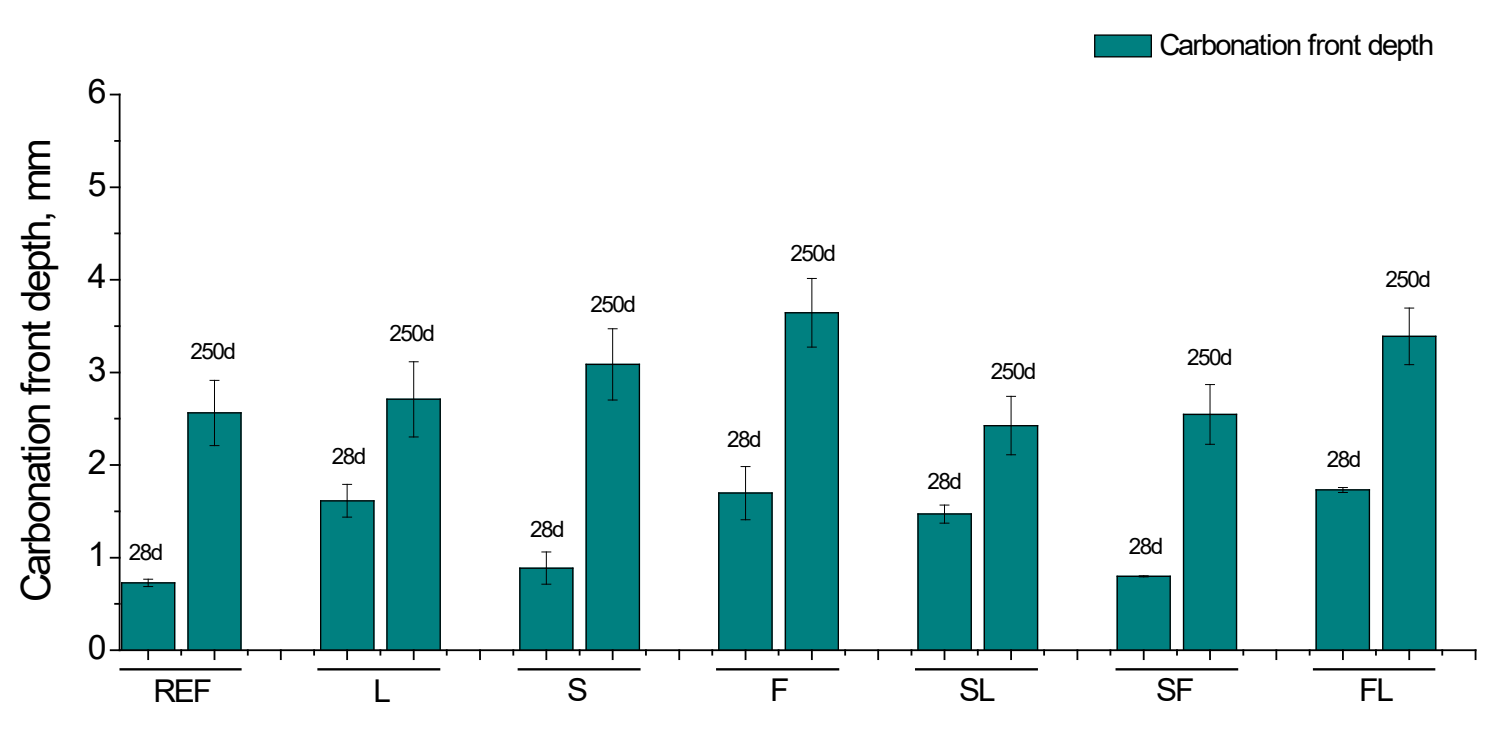

Figure 11. Carbonation front depths noted for the different binders studied.

\subsection{Mechanical Strengths}

The results of compressive strength are represented in Figure 12. At the age of 28 days, the highest values of this strength corresponded to REF and S specimens, followed by $\mathrm{F}$ and SF ones. Between 28 and 250 days, this parameter decreased for REF, SL, and SF series, being more noticeable this reduction for REF mortars, and it kept practically constant for the other binders studied. In the long term, S and F mortars showed higher compressive strength than REF. For the analyzed ternary binders, at 250 days, the compressive strength of the SF series was very similar to that noted for REF mortars, while it was slightly lower for SL and FL series compared to those reference specimens. Finally, the lowest compressive strength was obtained for $L$ mortars at 28 and 250 days.

The flexural strength results are depicted in Figure 13. At 28 days, this parameter was relatively similar for the REF, S, F, and SF series, being higher than the other binders studied. Generally, it was observed a decrease in flexural strength with time for the majority of the mortars. The reduction in this parameter was more notable for REF, S, and SF specimens. At 250 days, scarce differences in flexural strength have been noted between the different analyzed binders, being the values of this parameter in the range from 6 to $7 \mathrm{MPa}$ approximately for most of them.

\subsection{Ultrasonic Pulse Velocity}

The results of ultrasonic pulse velocity (UPV) are shown in Figure 14. At initial ages, this parameter was higher for the REF, F, SF, and S series compared to the other studied binders. In general, this parameter hardly increased or even slightly decreased with time for most of the binders. Along the studied time period, UPV values noted for the majority 
of the series were relatively similar, being in the range from 4200 to $4400 \mathrm{~m} / \mathrm{s}$ approximately. Lastly, the lowest UPV values have been overall noted for L mortars during the analyzed period of time.

$\square$ Compressive strength

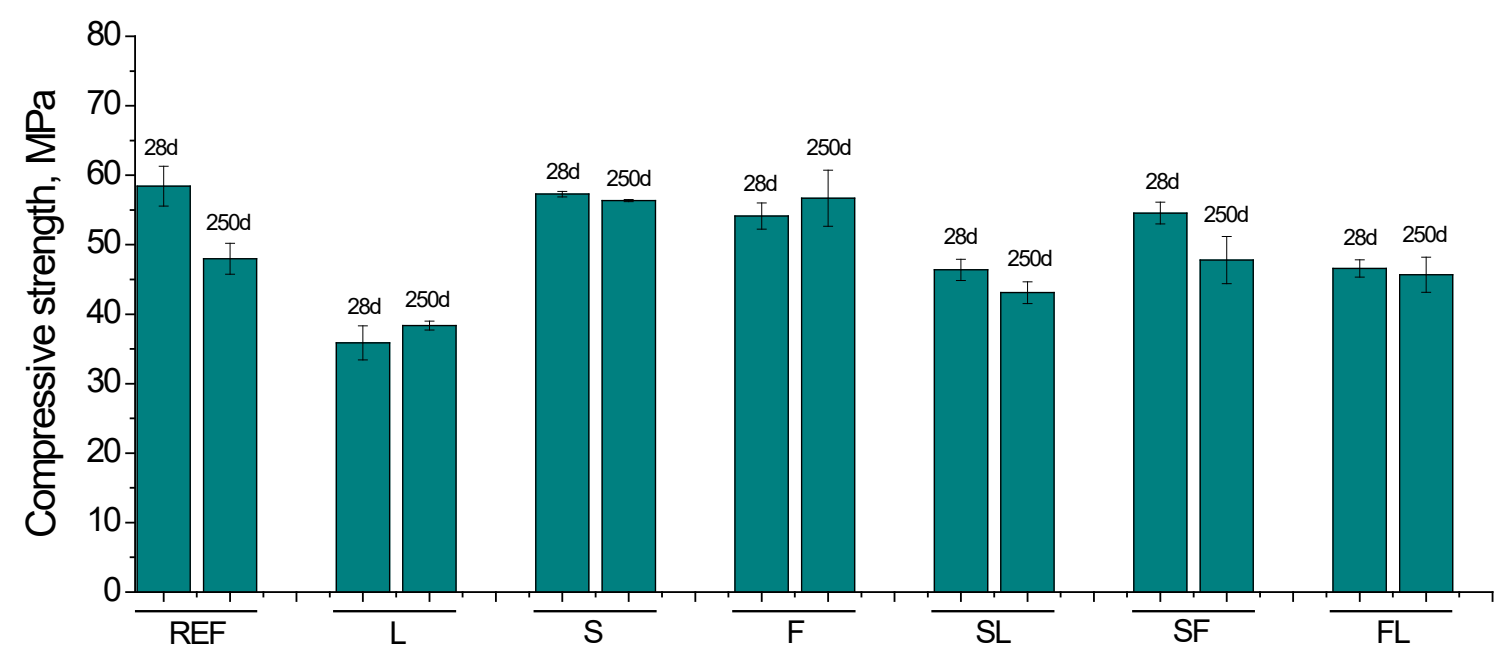

Figure 12. Compressive strength results for the studied binders.

$\square$ Flexural strength

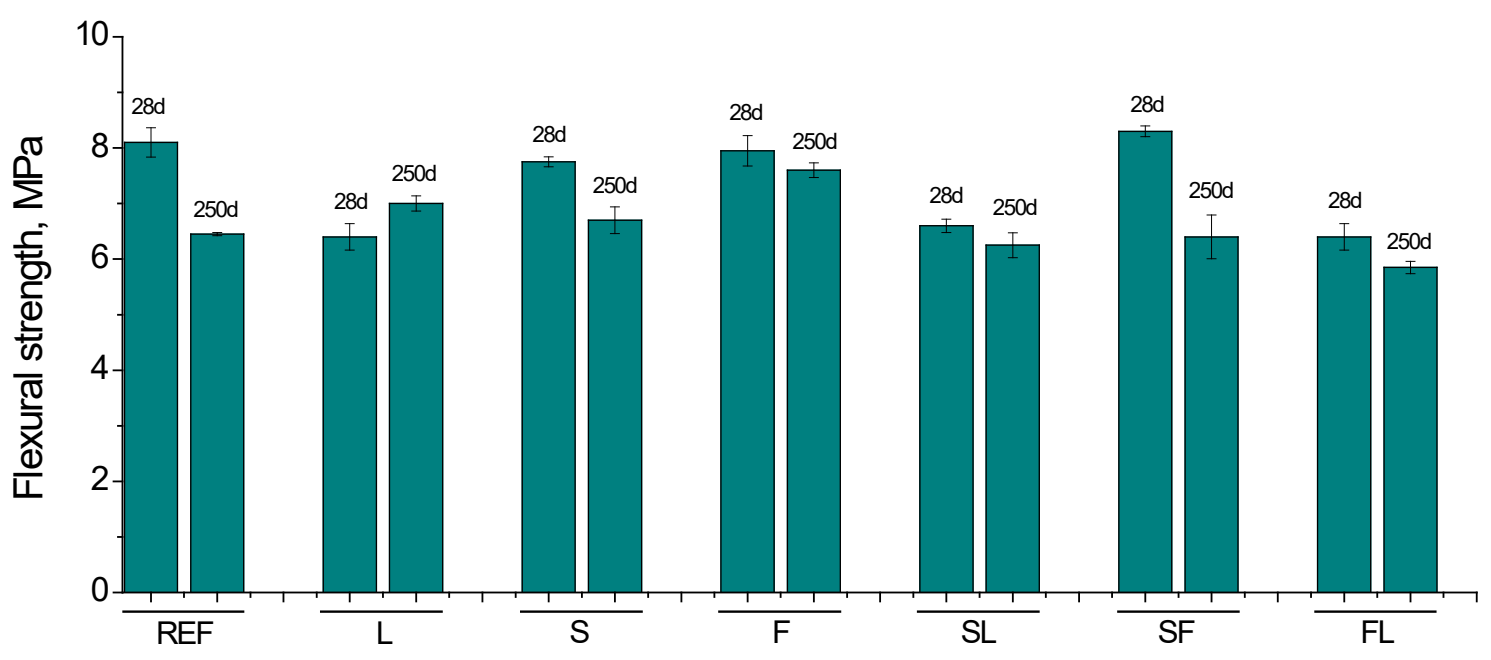

Figure 13. Results of flexural strength noted for the analyzed mortars. 


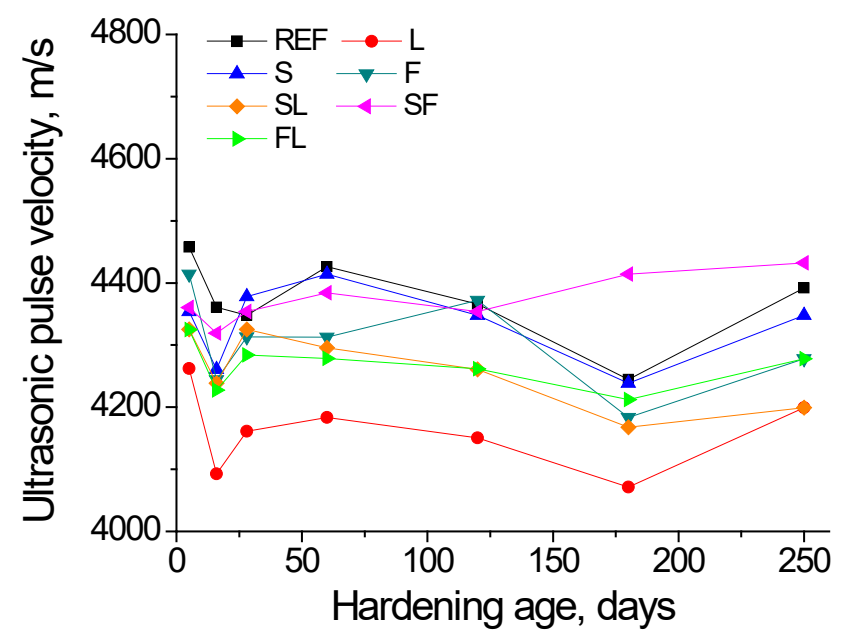

Figure 14. Ultrasonic pulse velocity results observed for the different types of mortars tested.

\section{Discussion}

\subsection{Microstructure Characterization}

With respect to the results of mercury intrusion porosimetry technique (see Figures 6 and 7), the very similar total porosity and the higher pore refinement, with a greater presence of finer pores, noted at 28 days for reference mortars and some of the binary and ternary binders with slag and fly ash (S, F and SF series), would be linked to the development of clinker and slag hydration [19,60] and fly ash pozzolanic reactions [13]. These reactions produced solid phases that progressively closed the microstructure, reducing the porosity of the material and increasing the percentage of pores with smaller diameters [10,18].

For initiating the development of fly ash pozzolanic reactions, it is needed the presence of enough portlandite produced by clinker hydration, so the effects of these pozzolanic reactions on the microstructure are generally delayed, compared to effects of slag and clinker hydration [13]. At 28 days, scarce differences in total porosity and pore size distributions were noted between the binary binder with fly ash (F series) and reference mortars (REF series) and those with only slag as an addition ( $S$ series). This would suggest that it has been produced noticeable progress in the short term of fly ash pozzolanic reactions. This result could be related to the environmental conditions in the exposure site up to 28 hardening days. In this period, it rained all days from 18 to 28 days, and in some of them, it was noted that daily rainfalls were higher than $15 \mathrm{~mm}$ (see Figure 5). In addition, in that period, the environmental relative humidity registered was relatively high (see Figure 3), reaching maximum values of this parameter around 100\% (see Figure 4). The combination of the high relative humidity and several rainy days in that period would produce a rise of water content in the specimens, which even probably were saturated with water in some time periods along the first 28 hardening days. The greater availability of water supplied by the environment would facilitate the development of hydration reactions of clinker components [33,60], so a higher presence of portlandite would be available at short ages. This would allow a sooner initiation of fly ash pozzolanic reactions and their greater development in the short term, as suggested by the mercury intrusion porosimetry results.

On the other hand, the temperature of the environment also has an influence on the development of the hydration and pozzolanic reactions [32,33,60-63]. In this line, it has been reported that low temperatures would slow down these abovementioned reactions [32,33,60-63]. Up to 28 hardening days, the temperatures registered in the exposure site were mild (see Figure 2), reaching a maximum value of $23^{\circ} \mathrm{C}$ and ranging the daily average temperature from 12 to $18^{\circ} \mathrm{C}$ (see Figure 4 ). Therefore, it would be expected that 
these temperatures in the exposure site would scarcely slow down the development of hydration and pozzolanic reactions $[32,60,61,63]$. These environmental conditions up to 28 hardening days (mild temperatures, high relative humidity, and several rainy days) would also have a beneficial effect on the slag hydration $[60,62,63]$, as suggested the similar pore size distribution and total porosity at that hardening time observed for $S$ mortars compared to REF ones because a relatively high presence of water provided by the environment would facilitate the slag hydration [33].

Regarding the analyzed ternary binders, the most refined pore structure at 28 hardenings was noted for the SF series, which combined both slag and fly ash additions. This could be due to the synergetic effects of the hydration of slag and pozzolanic reactions of fly ash [64], considering the previously discussed influence of the environment in the microstructure development, giving, as a result, a higher percentage of pores in the interval $<10 \mathrm{~nm}$ in this binder at that age compared to REF, $\mathrm{S}$ and $\mathrm{F}$ mortars, with similar total porosity. With respect to the ternary binders with limestone (SL and FL mortars), a slight loss of pore refinement at 28 days has been noted in comparison with the binary binders with slag and fly ash additions ( $\mathrm{S}$ and $\mathrm{F}$ series). This may be related to the presence of limestone, which is an addition without hydraulic or pozzolanic activity $[21,65]$, only having a filler effect in the microstructure, so its incorporation would not produce an additional solid phases formation, as occurred with fly ash and slag. Despite that, the development of slag hydration and fly ash pozzolanic reactions, favored by the high relative humidity and water provided by the environment, as has been previously explained, would reduce the influence of limestone in the microstructure of these ternary binders at 28 days. Finally, the less pore refinement and higher porosity noted for L mortars at that age would be due to the abovementioned effects of this not active addition, which would act as an inert filler material without reactivity [65].

From 28 to 250 days, it has been registered a rise of total porosity and a pore refinement loss for all the mortars studied. This may be related to the environmental conditions because part of that time period covered the summer season in the exposure site, in which it has been registered higher average temperatures (see Figure 4), a higher number of sunshine hours, lower relative humidity (see Figure 4) and very little rainfall (see Figure 5). These conditions would produce drying of the materials, giving as a result that less water was available for the development of hydration and pozzolanic reactions at later times [60,61], as well as the possible formation of shrinkage microcracking $[60,66,67]$. This would entail a rise of total porosity, also an increase in the proportion of pores with higher sizes, as revealed by the porosimetry results at 250 days. In addition, exposure to an outdoor environment may produce the development of carbonation, as can be observed in Figure 11. Several authors [68-70] have pointed out that in the long term, the carbonation process would lead to a reduction in porosity, particularly when ordinary Portland cement without additions is used, and to a reduction in pore refinement. Then, the rise of porosity with time noted for all the studied mortars would suggest that the drying shrinkage would be the harmful process prevailing in the exposure site at later ages.

Comparing the pore size distributions obtained at 250 days between the analyzed mortars, they overall agree with those noted at 28 days, already discussed. The pore structure was more refined for the F, S, SF, and REF series, showing the abovementioned effects of hydration and pozzolanic reactions $[10,13,60]$, as well as the synergistic effects of introducing fly ash and slag in the same binder [64]. On the contrary, mortars with limestone (L, SL, and FL series) showed less pore refinement, probably due to the fact that this addition does not have hydraulic or pozzolanic activity [65], as has been previously explained. Furthermore, several works $[32,36,71]$ have revealed that a relatively high hardening temperature may induce faster slag hydration, which produces the formation of dense hydrated phases around the particles without reacting, avoiding later hydration. This non-uniform distribution of the hydration products could lead to a less refined microstructure in the long term, with the presence of larger pores in the pore network 
$[32,36,71]$. This could also contribute to the relatively high coarsening of the pore structure between 28 and 250 days noted for binders with only slag as active addition (S and SL series), in combination with the effects of drying shrinkage and carbonation harmful processes.

On the other hand, when the mercury intrusion porosimetry results obtained in the long term for the real condition studied in this research are compared to the results noted in a previous work of the authors [42], in which mortars with the same compositions were exposed to an optimum laboratory condition, it is important to highlight the higher total porosities and lower microstructure refinement observed for all the mortars hardened under the real environment. As has been previously explained when it has been discussed the evolution of the pore network from 28 to 250 days, the environmental conditions in the real exposure site produced in the long term a progressive drying of the material $[60,61]$, making more difficult the development of slag and clinker hydration, as well as the fly ash pozzolanic reactions, which need the presence of enough water for their progress, also leading to the possible formation of shrinkage microcracking. This would not happen under an optimum laboratory condition, where there was enough water available for developing those reactions, and no drying process was produced. This would mainly explain the microstructural differences in the studied mortars between the real and optimum conditions. Furthermore, the carbonation process produced in the real condition could have also contributed to those differences.

The electrical resistivity allows obtaining information regarding the changes in the pore structure of cement-based materials, although it is greatly influenced by the drying process, which would modify the saturation degree of the material [53,72]. This drying produces a lessening of the volume of electrolyte, which fills the pore structure of the material, giving, as a result, an increase in the electrical resistivity [72-74]. The reduction in porosity and the greater presence of pores with finer sizes would also lead to a reduction in the amount of electrolyte present in the material, also producing a rise of the resistivity [75-77]. Here has been noted a progressive increase with time of this parameter for all the series tested (see Figure 8). In the short term, until 28 days approximately, the rising tendency of the electrical resistivity would be more related to the microstructure closing, as a consequence of the development of hydration and pozzolanic reactions, facilitated by the high environmental relative humidity during that time period (see Figures 3 and 4), as has been explained for porosimetry results. However, since then, this parameter has increased with a progressively higher rate, in particular during the summer season. The pore size distributions noted at 250 days showed a lessening of pore structure refinement, so the long-term increase in resistivity may be more related to the drying of the material, which would be compatible with the conditions of the exposure site in the warmer months (higher temperature, lower relative humidity, higher number of daylight hours and scarce rainfall). In addition, comparing the electrical resistivity results noted in this work for the analyzed real environment and those obtained for mortars with the same composition hardened in an optimum laboratory condition [42], the values of this parameter were generally higher for the real environment, whereas their microstructure was less refined than in the optimum condition. This would corroborate the abovementioned effect of the drying process in the resistivity evolution for mortars exposed to the real environment.

Despite that, another factor that could also have an influence on the differences between the porosimetry and electrical resistivity results at later ages would be the different types of samples used for both techniques. For mercury intrusion porosimetry, the tested pieces were extracted from small cylinders $(5 \mathrm{~cm}$ diameter and $6 \mathrm{~cm}$ height). Nevertheless, the electrical resistivity was measured in another kind of cylindrical samples, with greater volume and dimensions $(10 \mathrm{~cm}$ diameter and $22 \mathrm{~cm}$ height). The smaller size of the cylinders used for obtaining the porosimetry samples would entail a faster drying of the entire sample, showing more uniform effects of the environment in the microstructure. In the case of the larger cylinders in which the electrical resistivity has 
been determined, the effects of the environment, especially the drying process, in the internal part of the sample would be delayed, keeping during more time enough electrolyte available in the microstructure for developing the hydration and pozzolanic reactions, resulting in a higher microstructure refinement in that internal part of the cylinders. The electrical resistivity measurements permit to get more global information about the pores of the sample, so this parameter may be influenced by the possible different microstructure development between the internal and external parts of the sample. This could contribute to explain the different results between porosimetry and electrical resistivity, together with the abovementioned influence of the drying in this parameter.

In relation to the resistivity noted at later ages for the analyzed binders, with a similar drying degree produced by the exposure environment, several coincidences with the previously discussed results have been observed. Firstly, mortars with active additions showed higher electrical resistivity, being in accordance with the results pointed out by other authors [72]. The greater values at 250 days of this parameter noted for F and SF mortars, in comparison with the rest of the binders, would agree with their higher percentage of smaller pores at that age. Moreover, the lower resistivity values for fly ash binders in the short term, compared to specimens with slag, and their progressive growth with time, even exceeding in the long term the values noted for slag binders, would suggest the delay of the pozzolanic reactions of fly ash respect to the hydration of slag $[13,17]$, already explained. Finally, the limestone addition produced a reduction in electrical resistivity when it was incorporated into the binder, as showed the comparison between mortars with slag (SL series had lower resistivity compared to S and SF series) and between those with fly ash (FL series had lower resistivity in comparison with SF and F series). This would be in accordance with pore size distributions, being in relation to the only filler effect of limestone [21,65], without hydraulic or pozzolanic activity, previously discussed.

\subsection{Durability and Mechanical Parameters}

With respect to the durability of the studied binders, the overall reduction with time of the steady-state chloride diffusion coefficient (see Figure 10) would agree with the increase in electrical resistivity, suggesting a pore refinement with time, which would not be in line with the evolution of pore size distributions. The diffusion coefficient has been calculated from the electrical resistivity of water-saturated cylinders with $22 \mathrm{~cm}$ height and $10 \mathrm{~cm}$ diameter (see Section 2.6), analogous to those used for studying the resistivity in the non-saturated material. Among the arguments previously explained for justifying the electrical resistivity results, the influence of the saturation degree in the measurements would not be applicable for the diffusion coefficient because the samples were saturated in the water previously to register their electrical resistivity. Therefore, the differences between the diffusion coefficient results and the pore size distributions would be due to the possible higher microstructure refinement in the internal part of the samples, compared to their external part, discussed with detail for the electrical resistivity results in the previous subsection.

At 28 days, the diffusion coefficient results showed similarities with those obtained in the microstructure characterization. The lower coefficients noted for reference mortars and those with slag (REF, S, SF, and SL series), compared to other series with fly ash (F and FL mortars), would show once again the delay the pozzolanic reactions of fly ash with respect to the hydration of clinker and slag $[13,17]$, although this delay seemed to be more noticeable in the diffusion coefficient than in the pore size distributions. The slight decrease with time of this coefficient observed for REF and L mortars would suggest that the drying effect of the environment would affect the internal part of their samples earlier than in the specimens with active additions (slag and/or fly ash), probably as a consequence of a less refined microstructure. On the other hand, the environmental influence in the core part of the sample would be lower in the long term for those series 
with active additions, as would indicate their notable decrease with time of diffusion coefficient. This would be in keeping with their greater refinement of pores, which would make more difficult the drying of the microstructure electrolyte, thus delaying the harmful effects of the environment. In this line, it is interesting to highlight that S, F, SL, $\mathrm{SF}$, and FL series showed lower diffusion coefficients than reference specimens. With regard to the comparison of the long-term results of this parameter between the real environment studied in this research and those previously published for the same materials under an optimum condition [42], it has been observed higher diffusion coefficient values in the real environment for all the mortars. This would agree with the differences of mercury intrusion porosimetry results between both conditions, already discussed. However, it is interesting to highlight that these differences were lower for this coefficient, compared to other parameters analyzed, which would be in keeping with the possible less influence of the real environment in the core part of the sample, at least until the latest studied age of 250 days.

The lower values of the water after absorption after immersion noted for S, F, and SF series compared to the other studied mortars would be consistent with the other parameters described. Nevertheless, the small changes with time and the overall slight differences between the analyzed mortars regarding the water absorption after immersion (see Figure 9) would not totally agree with the results previously discussed. The relatively similar values of the water absorption, independently of the binder, may be influenced by the method used for obtaining this parameter, defined in the ASTM Standard C642-06 [54]. The initial phase of this method required keeping the specimens at 100 to $110^{\circ} \mathrm{C}$ at least $24 \mathrm{~h}$ before they were saturated [54]. This drying at high temperature could produce the development of shrinkage cracks in the mortars [16,67,78], which would cover up and notably remove the influence of the environment, entailing a more uniform performance of the mortars in relation to the water absorption parameter.

The development of carbonation with time in the samples (see Figure 11) would be expected due to their exposure to a real outdoor environmental condition, in contrast with the lack of carbonation of the same materials hardened under an optimum laboratory condition that was studied in previous work [42]. The differences regarding the carbonation front depths between the analyzed binders in this real environment were not very high. In general, these depths were greater during the analyzed period of time for $F$ and FL mortars, which could be explained in relation to the consumption of portlandite during the fly ash pozzolanic reactions, as has been reported by several authors [16,69]. Moreover, the carbonation process would produce a reduction in pore refinement due to the formation of silica as a product of the decomposition of C-S- $\mathrm{H}$ gel caused by the $\mathrm{CO}_{2}$ exposure $[15,16,70]$. Then, the rise with time of carbonation depths would agree with the results of pore size distributions, showing that carbonation could also contribute to the loss of microstructure refinement, in addition to the already explained effects of drying shrinkage.

The decreasing tendency with time of the mechanical strengths (see Figures 12 and 13) for most of the studied binders would be in consonance with the reduction in porosity and the coarsening of pore structure discussed before. This may be related to the conditions of the exposure site, mainly with the drying of the materials in the long term $[34,67,79]$, although the carbonation could also have helped to the reduction in mechanical performance because this process has harmful effects in these properties, according to several authors $[80,81]$. It was noticeable that the relatively high compressive and flexural strength at 28 days was noted for the F series, very similar to reference mortars and binary binder with slag ( $\mathrm{S}$ series). This result would also be consistent with those obtained with mercury intrusion porosimetry, pointing out a possible moderate development of fly ash pozzolanic reactions, probably favored by the high relative humidity and the heavy rain registered in the exposure station at short hardening ages, as has been explained. In addition, the incorporation of limestone in ternary binders (FL and SL series) generally reduced the mechanical performance of the mortars, compared to the rest of binders with 
slag and/or fly ash (S, F, and SF series). These results were also coincident with most of those already described, showing the effects of this non-active addition [21,65]. Lastly, it is interesting to highlight the similar or even better flexural and compressive strengths observed at 250 days for most of the binders with at least one active addition (slag and/or fly ash) in comparison with reference mortars.

The ultrasonic pulse velocity (UPV) results were overall in keeping with those obtained for mechanical strengths. The higher UPV values noted at early ages for REF, F, $\mathrm{SF}$, and S mortars (see Figure 14) would agree with their slightly higher compressive and flexural strengths at 28 days, showing the effects of hydration and pozzolanic reactions $[10,13,60]$, favored by the mild environmental conditions in the short term, as has been discussed in the microstructure characterization. The constant or decreasing trend of the UPV with time for most of the binders studied would be in consonance with the general reduction in the mechanical strengths from 28 to 250 days, produced by the explained influence of the environment. The smallest UPV registered for the L series along the analyzed exposure period coincided with their lowest compressive strengths, corroborating the abovementioned influence of the limestone addition in the mechanical behavior of the mortars under the studied environment.

Finally, if the mechanical performance results obtained in the real environment studied in this research are compared to those noted in a previous work of the authors [42], in which the influence of an optimum condition in mortars with the same composition was studied, it is interesting to point out that in the long term the mechanical strengths and the ultrasonic pulse velocity values were generally lower in the real environment than in the optimum condition for all the analyzed mortars. This would be in agreement with the results of comparing both environments for the other parameters studied, which were related to the microstructure characterization and durability-related properties. According to the discussion of those results, already explained, the high relative humidity available in the optimum environment would allow adequate development of hydration and pozzolanic reactions [13,17,33,42], improving the mechanical performance of the mortars. On the other hand, the harmful processes developed in the real environment, such as the drying shrinkage and the carbonation process, would produce a worsening of the mechanical performance of the materials $[34,67,79]$ compared to the optimum condition, as has been observed here.

\section{Conclusions}

The main conclusions that can be obtained from the results previously discussed can be summarized as follows:

- The relative mild and humid environmental conditions during the first weeks of the exposure period improved the microstructure and the properties of the studied mortars, facilitating the development of clinker and slag hydration, as well as the pozzolanic reactions of fly ash at early ages;

- The studied binders generally showed an increase in total porosity, a loss of pore refinement, a rise of the carbonation front depths, and a reduction in their mechanical strengths with time. This could be due to the long-term effects of the warm environmental conditions in the exposure site, which would produce a progressive drying of the material, making more difficult the development of hydration and pozzolanic reactions and probably producing the formation shrinkage microcracking. This would give, as a result, the worsening with the time of the performance of the mortars, to which the development of carbonation would also contribute, although to a lesser extent. In addition, these harmful effects would also lead to the worst long-term behavior of the mortars exposed to the studied real environment, compared to their performance under an optimum laboratory condition pointed out in previous work; 
- The electrical resistivity showed a progressive rise with age for all the studied binders, which would be due to the reduction in the amount of the electrolyte that fills the microstructure of the material, mainly produced by the drying process as a consequence of the exposure to the real environment. However, this increase with time of the resistivity could also be related to a different microstructure development in the internal and external parts of the samples used for measuring this parameter due to their higher size and volume than those tested with the other techniques. This would produce a denser microstructure of the material in the samples' core part, influencing the resistivity. In addition, the reduction with the age of the steady-state chloride diffusion coefficient observed would be in keeping with the increase in electrical resistivity, which would also point out the abovementioned possible differences between the internal and external parts of the specimens;

- The results of the water absorption after immersion would be affected by the drying in an oven at $100^{\circ} \mathrm{C}$ established in the experimental procedure performed, masking and notably removing the influence of the environmental conditions in this parameter. Despite that, the binary binders with slag and fly ash ( $\mathrm{S}$ and F series) and the ternary binder, which incorporated both additions (SF series), showed lower water absorption values than other analyzed mortars;

- The differences in relation to the carbonation front depths between the binders studied were not high, although in general, they were greater for binders with only fly ash as active addition (FL and F series). This result may be due to their lower portlandite content as a consequence of the development of the pozzolanic reactions of fly ash;

- After 250 days, the binary binders with slag and fly ash (S and F mortars) and the ternary binder, which incorporated both additions (SF series) overall, showed higher pore refinement and similar or even better mechanical performance than reference mortars without additions. This would be due to the effects of the hydration of slag and the pozzolanic reactions of fly ash, as well as by the synergetic effect of combining both additions in the ternary binder;

- The incorporation of limestone in the ternary binders (FL and SL mortars) would entail a lower pore structure refinement and a reduction in the mechanical strengths, compared to the other binders with slag and/or fly ash (S, F, and SF series). This may be explained in relation to the lack of hydraulic or pozzolanic activity of limestone addition, so its effects are limited in comparison with slag and fly ash, acting only as a filler material.

Author Contributions: Conceptualization, J.M.O., J.I.-G., and T.R.-H.; methodology, J.I.-G., J.M.O., and T.R.-H.; investigation, J.I.-G. and J.M.O.; data curation, J.I.-G. and J.M.O.; writing-original draft preparation, J.I.-G.; writing-review and editing, J.M.O.; supervision, J.M.O. and T.R.-H.; funding acquisition, J.M.O. The results included in this paper have been obtained in the Ph.D.thesis carried out by J.I.-G. at University of Alicante (Spain), under the supervision of J.M.O. and T.R.-H. All authors have read and agreed to the published version of the manuscript.

Funding: This work was supported by the Conselleria de Educación, Investigación, Cultura y Deporte (presently re-named as Conselleria de Innovación, Universidades, Ciencia y Sociedad Digital) de la GeneralitatValenciana, Spain (grant code GV/2019/070).

Institutional Review Board Statement: Not applicable.

Informed Consent Statement: Not applicable.

Data Availability Statement: The data that support the findings of this study are available from the corresponding author, J.M.O., upon reasonable request.

Acknowledgments: Authors wish to thank Cementos Portland Valderrivas S.A. for providing the ordinary Portland cement CEM I 42.5 R and the limestone, fly ash, and ground granulated blastfurnace slag additions used in this study.

Conflicts of Interest: The authors declare no conflict of interest. 


\section{References}

1. Benhelal, E.; Shamsaei, E.; Rashid, M.I. Challenges against $\mathrm{CO}_{2}$ abatement strategies in cement industry: A review. J. Environ. Sci. 2021, 104, 84-101, doi:10.1016/j.jes.2020.11.020.

2. Zhang, C.-Y.; Yu, B.; Chen, J.-M.; Wei, Y.-M. Green transition pathways for cement industry in China. Resour. Conserv. Recycl. 2021, 166, doi:10.1016/j.resconrec.2020.105355.

3. Rodríguez, G.; Medina, C.; Alegre, F.J.; Asensio, E.; Sánchez de Rojas, M.I. Assessment of Construction and Demolition Waste plant management in Spain: in pursuit of sustainability and eco-efficiency. J. Clean. Prod. 2015, 90, 16-24, doi:10.1016/j.jclepro.2014.11.067.

4. Coppola, L.; Bellezze, T.; Belli, A.; Bignozzi, M.C.; Bolzoni, F.; Brenna, A.; Cabrini, M.; Candamano, S.; Cappai, M.; Caputo, D.; et al. Binders alternative to Portland cement and waste management for sustainable construction-part 1. J. Appl. Biomater. Funct. Mater. 2018, 16, 186-202, doi:10.1177/2280800018782845.

5. Valipour, M.; Shekarchi, M.; Arezoumandi, M. Chlorine diffusion resistivity of sustainable green concrete in harsh marine environments. J. Clean. Prod. 2017, 142, 4092-4100, doi:10.1016/j.jclepro.2016.10.015.

6. Demirboğa, R. Thermal conductivity and compressive strength of concrete incorporation with mineral admixtures. Build. Environ. 2007, 42, 2467-2471, doi:10.1016/j.buildenv.2006.06.010.

7. Ganjian, E.; Pouya, H.S. Effect of magnesium and sulfate ions on durability of silica fume blended mixes exposed to the seawater tidal zone. Cem. Concr. Res. 2005, 35, 1332-1343, doi:10.1016/j.cemconres.2004.09.028.

8. Ponikiewski, T.; Gołaszewski, J. The effect of high-calcium fly ash on selected properties of self-compacting concrete. Arch. Civ. Mech. Eng. 2014, 14, 455-465, doi:10.1016/j.acme.2013.10.014.

9. Tremiño, R.M.; Real-Herraiz, T.; Letelier, V.; Branco, F.G.; Ortega, J.M. Effects after 1500 hardening days on the microstructure and durability-related parameters of mortars produced by the incorporation of waste glass powder as a clinker replacement. Sustainability 2021, 13, 3979, doi:10.3390/su13073979.

10. Bijen, J. Benefits of slag and fly ash. Constr. Build. Mater. 1996, 10, 309-314, doi:10.1016/0950-0618(95)00014-3.

11. Wang, J.; Zhang, Y.; Cui, K.; Fu, T.; Gao, J.; Hussain, S.; AlGarni, T.S. Pyrometallurgical recovery of zinc and valuable metals from electric arc furnace dust-A review. J. Clean. Prod. 2021, 298, doi:10.1016/j.jclepro.2021.126788.

12. Cui, K.; Zhang, Y.; Fu, T.; Hussain, S.; Algarni, T.S.; Wang, J.; Zhang, X.; Ali, S. Effects of $\mathrm{Cr}_{2} \mathrm{O}_{3}$ content on microstructure and mechanical properties of $\mathrm{Al}_{2} \mathrm{O}_{3}$ matrix composites. Coatings 2021, 11, 234, doi:10.3390/coatings11020234.

13. Wang, A.; Zhang, C.; Sun, W. Fly ash effects. Cem. Concr. Res. 2004, 34, 2057-2060, doi:10.1016/j.cemconres.2003.03.001.

14. Chindaprasirt, P.; Kroehong, W.; Damrongwiriyanupap, N.; Suriyo, W.; Jaturapitakkul, C. Mechanical properties, chloride resistance and microstructure of Portland fly ash cement concrete containing high volume bagasse ash. J. Build. Eng. 2020, 31, doi:10.1016/j.jobe.2020.101415.

15. Taylor, H.F.W. Cement Chemistry, 2nd ed.; Thomas Telford Publishing: London, UK, 1997; ISBN 978-0727725929.

16. Neville, A.M. Properties of concrete, 4th ed.; Pearson Education Limited: Harlow, UK, 1995.

17. Papadakis, V.G. Effect of fly ash on Portland cement systems. Cem. Concr. Res. 1999, 29, 1727-1736, doi:10.1016/S00088846(99)00153-2.

18. Wedding, P.; Manmohan, D.; Mehta, P. Influence of Pozzolanic, Slag, and Chemical Admixtures on Pore Size Distribution and Permeability of Hardened Cement Pastes. Cem. Concr. Aggreg. 1981, 3, 63, doi:10.1520/CCA10203J.

19. Bouikni, A.; Swamy, R.N.; Bali, A. Durability properties of concrete containing $50 \%$ and $65 \%$ slag. Constr. Build. Mater. 2009, 23 , 2836-2845, doi:10.1016/j.conbuildmat.2009.02.040.

20. Ortega, J.M.; Sánchez, I.; Climent, M.A. Durability related transport properties of OPC and slag cement mortars hardened under different environmental conditions. Constr. Build. Mater.2012, 27, 176-183, doi:10.1016/j.conbuildmat.2011.07.064.

21. Dhandapani, Y.; Santhanam, M.; Kaladharan, G.; Ramanathan, S. Towards ternary binders involving limestone additions - A review. Cem. Concr. Res. 2021, 143, doi:10.1016/j.cemconres.2021.106396.

22. Hadji, T.; Guettala, S.; Quéneudec, M. Mix design of high performance concrete with different mineral additions. World J. Eng. 2021, doi:10.1108/WJE-12-2020-0650.

23. Marchetti, G.; Irassar, E.F.; Rahhal, V.F. Effects of packing density and water film thickness on fresh and hardened properties of ternary cement pastes. Adv. Cem. Res. 2020, 32, 444-455, doi:10.1680/jadcr.18.00133.

24. AENOR UNE-EN 197-1:2011. Composición, Especificaciones y Criterios de Conformidad de los Cementos Comunes; Asociación Española de Normalización y Certificación: Madrid, Spain, 2011.

25. Dadsetan, S.; Bai, J. Mechanical and microstructural properties of self-compacting concrete blended with metakaolin, ground granulated blast-furnace slag and fly ash. Constr. Build. Mater. 2017, 146, 658-667, doi:10.1016/j.conbuildmat.2017.04.158.

26. Ban, C.C.; Sern, L.J.; Jasme, N. The mechanical strength and drying shrinkage behavior of high performance concrete with blended mineral admixture. J. Teknol. 2019, 81, 59-67, doi:10.11113/jt.v81.13209.

27. Radlinski, M.; Olek, J. Investigation into the synergistic effects in ternary cementitious systems containing portland cement, fly ash and silica fume. Cem. Concr. Compos. 2012, 34, 451-459, doi:10.1016/j.cemconcomp.2011.11.014.

28. De Weerdt, K.; Kjellsen, K.O.; Sellevold, E.; Justnes, H. Synergy between fly ash and limestone powder in ternary cements. Cem. Concr. Compos. 2011, 33, 30-38, doi:10.1016/j.cemconcomp.2010.09.006.

29. Cordeiro, G.C.; Toledo Filho, R.D.; Tavares, L.M.; Fairbairn, E.M.R. Experimental characterization of binary and ternary blended-cement concretes containing ultrafine residual rice husk and sugar cane bagasse ashes. Constr. Build. Mater. 2012, 29, 641-646, doi:10.1016/j.conbuildmat.2011.08.095. 
30. Radwan, M.K.H.; Onn, C.C.; Mo, K.H.; Yap, S.P.; Ng, C.G.; Yusoff, S. Eco-mechanical performance of binary and ternary cement blends containing fly ash and slag. Proc. Inst. Civ. Eng. Eng. Sustain. 2020, 174, 23-36, doi:10.1680/jensu.20.00009.

31. Bumanis, G.; Zorica, J.; Bajare, D. Properties of foamed lightweight high-performance phosphogypsum-based ternary system binder. Appl. Sci. 2020, 10, 6222, doi:10.3390/APP10186222.

32. Detwiler, R.J.; Kjellsen, K.O.; Gjorv, O.E. Resistance to chloride intrusion of concrete cured at different temperatures. Mater. J. 1991, 88, 19-24.

33. Çakır, Ö.; Aköz, F. Effect of curing conditions on the mortars with and without GGBFS. Constr. Build. Mater. 2008, 22, 308-314, doi:10.1016/j.conbuildmat.2006.08.013.

34. Ramezanianpour, A.A.; Malhotra, V.M. Effect of curing on the compressive strength, resistance to chloride-ion penetration and porosity of concretes incorporating slag, fly ash or silica fume. Cem. Concr. Compos. 1995, 17, 125-133, doi:10.1016/09589465(95)00005-W.

35. Thomas, M.D.A.; Scott, A.; Bremner, T.; Bilodeau, A.; Day, D. Performance of slag concrete in marine environment. ACI Mater. J.2008, 105, 628-634.

36. Geiseler, J.; Kollo, H.; Lang, E. Influence of blast furnace cements on durability of concrete structures. ACI Mater. J. 1995, 92, 252-257.

37. Shattaf, N.R.; Alshamsi, A.M.; Swamy, R.N. Curing/environment effect on pore structure of blended cement concrete. J. Mater. Civ. Eng. 2001, 13, 380-388, doi:10.1061/(ASCE)0899-1561(2001)13:5(380).

38. Polder, R.B.; De Rooij, M.R. Durability of marine concrete structures-Field investigations and modelling. Heron 2005, 50, 133154.

39. Thomas, M.D.; Matthews, J. Performance of pfa concrete in a marine environment-10-year results. Cem. Concr. Compos. 2004, 26, 5-20, doi:10.1016/S0958-9465(02)00117-8.

40. Chalee, W.; Jaturapitakkul, C.; Chindaprasirt, P. Predicting the chloride penetration of fly ash concrete in seawater. Mar. Struct. 2009, 22, 341-353, doi:10.1016/j.marstruc.2008.12.001.

41. European Committee for Standardization. EN 1992-1-1 Eurocode 2: Design of Concrete Structures - Part 1-1: General Rules and Rules for Buildings; Committee European Normalization (CEN): Brussels, Belgium, 2004.

42. Ibáñez-Gosálvez, J.; Real-Herraiz, T.; Ortega, J.M. Microstructure, durability and mechanical properties of mortars prepared using ternary binders with addition of slag, fly ash and limestone. Appl. Sci. 2021, 11, 6388, doi:10.3390/app11146388.

43. AENOR UNE-EN 196-1:2005. Métodos de Ensayo de Cementos. Parte 1: Determinación de Resistencias Mecánicas; Asociación Española de Normalización y Certificación: Madrid, Spain, 2005.

44. Ortega, J.M.; Sánchez, I.; Cabeza, M.; Climent, M.A. Short-Term Behavior of Slag Concretes Exposed to a Real In Situ Mediterranean Climate Environment. Materials 2017, 10, 915.

45. Diamond, S. Mercury porosimetry. Cem. Concr. Res.2000, 30, 1517-1525, doi:10.1016/S0008-8846(00)00370-7.

46. Ouellet, S.; Bussière, B.; Aubertin, M.; Benzaazoua, M. Microstructural evolution of cemented paste backfill: Mercury intrusion porosimetry test results. Miner. Eng. 2007, 37, 1654-1665, doi:10.1016/j.cemconres.2007.08.016.

47. Horpibulsuk, S.; Rachan, R.; Chinkulkijniwat, A.; Raksachon, Y.; Suddeepong, A. Analysis of strength development in cementstabilized silty clay from microstructural considerations. Constr. Build. Mater. 2010, 24, 2011-2021, doi:10.1016/j.conbuildmat.2010.03.011.

48. Pedeferri, P.; Bertolini, L. La Durabilità del Calcestruzzo Armato; Mc Graw-Hill Education: Milano, Italy, 2000; ISBN 9788838608452.

49. Ho, L.S.; Nakarai, K.; Duc, M.; Kouby, A.L.; Maachi, A.; Sasaki, T. Analysis of strength development in cement-treated soils under different curing conditions through microstructural and chemical investigations. Constr. Build. Mater. 2018, 166, 634-646, doi:10.1016/j.conbuildmat.2018.01.112.

50. Polder, R.; Andrade, C.; Elsener, B.; Vennesland, Ø.; Gulikers, J.; Weidert, R.; Raupach, M. Test methods for on site measurement of resistivity of concrete. Mater. Struct. 2000, 33, 603-611, doi:10.1007/BF02480599.

51. Lübeck, A.; Gastaldini, A.L.G.; Barin, D.S.; Siqueira, H.C. Compressive strength and electrical properties of concrete with white Portland cement and blast-furnace slag. Cem. Concr. Compos.2012, 34, 392-399, doi:10.1016/j.cemconcomp.2011.11.017.

52. AENOR UNE 83988-2:2014. Durabilidad del Hormigón. Métodos de Ensayo. Determinación de la Resistividad Eléctrica. Parte 2: Método de las Cuatro Puntas o de Wenner; Asociación Española de Normalización y Certificación: Madrid, Spain, 2014.

53. Andrade, C.; Climent, M.A. Recomendaciones sobre determinación de la resistividad eléctrica del hormigón in situ mediante el método de las cuatro puntas y del disco; ALCONPAT Internacional: Mérida, Yucatán, Mexico, 2020, p. 11, doi: 10.21041/AlconpatInternacional/RecTec/2020-05-resistividadinsitu

54. ASTM C642-06. Standard Test Method for Density, Absorption, and Voids in Hardened Concrete; ASTM International: West Conshohocken, PA, USA, 2006; p. 3.

55. ASTM C1202-12. Standard Test Method for Electrical Indication of Concretes Ability to Resist Chloride Ion Penetration; ASTM International: West Conshohocken, PA, USA, 2012.

56. Andrade, C.; Alonso, C.; Arteaga, A.; Tanner, P. Methodology based on the electrical resistivity for the calculation of reinforcement service life. In Proceedings of the 5th CANMET/ACI International Conference on Durability of Concrete, Supplementary Papers; Malhotra, V.M., Ed.; American Concrete Institute: Barcelona, Spain, 4-9 June 2000; pp. 899-915.

57. RILEM CPC-18. Measurement of hardened concrete carbonation depth. Mater. Struct. 1988, 21, $453-455$.

58. AENOR UNE-EN 1015-11:1999. Métodos de Ensayo de los Morteros Para Albañilería. Parte 11: Determinación de la Resistencia a Flexión y a Compresión del Mortero Endurecido; Asociación Española de Normalización y Certificación: Madrid, Spain, 1999. 
59. AENOR UNE-EN 12504-4:2006. Ensayos de Hormigón en Estructuras. Parte 4: Determinación de la Velocidad de los Impulsos Ultrasónicos; Asociación Española de Normalización y Certificación: Madrid, Spain, 2006.

60. Ortega, J.M.; Sánchez, I.; Climent, M.A. Impedance spectroscopy study of the effect of environmental conditions in the microstructure development of OPC and slag cement mortars. Arch. Civ. Mech. Eng. 2015, 15, doi:10.1016/j.acme.2014.06.002.

61. Ortega, J.M.; Sánchez, I.; Climent, M.A. Impedance spectroscopy study of the effect of environmental conditions on the microstructure development of sustainable fly ash cement mortars. Materials 2017, 10, 1130, doi:10.3390/ma10101130.

62. Barnett, S.J.; Soutsos, M.N.; Millard, S.G.; Bungey, J.H. Strength development of mortars containing ground granulated blastfurnace slag: Effect of curing temperature and determination of apparent activation energies. Cem. Concr. Res. 2006, 36, 434-440, doi:10.1016/j.cemconres.2005.11.002.

63. Escalante-García, J.I.; Sharp, J.H. Effect of temperature on the hydration of the main clinker phasesin Portland cements: Part II, blended cements. Cem. Concr. Res. 1998, 28, 1259-1274.

64. Hale, W.M.; Freyne, S.F.; Bush Jr., T.D.; Russell, B.W. Properties of concrete mixtures containing slag cement and fly ash for use in transportation structures. Constr. Build. Mater. 2008, 22, 1990-2000, doi:10.1016/j.conbuildmat.2007.07.004.

65. Meddah, M.S.; Lmbachiya, M.C.; Dhir, R.K. Potential use of binary and composite limestone cements in concrete production. Constr. Build. Mater. 2014, 58, 193-205, doi:10.1016/j.conbuildmat.2013.12.012.

66. Ma, B.-G.; Wen, X.-D.; Wang, M.-Y.; YAN, J.-J.; Gao, X.-J. Drying Shrinkage of Cement-Based Materials Under Conditions of Constant Temperature and Varying Humidity. J. China Univ. Min. Technol. 2007, 17, 428-431, doi:10.1016/S1006-1266(07)601199.

67. Kanna, V.; Olson, R.A.; Jennings, H.M. Effect of shrinkage and moisture content on the physical characteristics of blended cement mortars. Cem. Concr. Res. 1998, 28, 1467-1477.

68. Anstice, D.J.; Page, C.L.; Page, M.M. The pore solution phase of carbonated cement pastes. Cem. Concr. Res. 2005, 35, 377-383, doi:10.1016/j.cemconres.2004.06.041.

69. Ngala, V.T.; Page, C.L. Effects of carbonation on pore structure and diffusional properties of hydrated cement pastes. Cem. Concr. Res. 1997, 27, 995-1007, doi:10.1016/S0008-8846(97)00102-6.

70. Díaz, B.; Freire, L.; Nóvoa, X.R.; Pérez, M.C. Chloride and $\mathrm{CO}_{2}$ transport in cement paste containing red mud. Cem. Concr. Compos. 2015, 62, 178-186, doi:10.1016/j.cemconcomp.2015.02.011.

71. Aldea, C.-M.; Young, F.; Wang, K.; Shah, S.P. Effects of curing conditions on properties of concrete using slag replacement. Cem. Concr. Res. 2000, 30, 465-472, doi:10.1016/S0008-8846(00)00200-3.

72. De Grazia, M.T.; Deda, H.; Sanchez, L.F.M. The influence of the binder type \&amp; aggregate nature on the electrical resistivity of conventional concrete. J. Build. Eng. 2021, 43, doi:10.1016/j.jobe.2021.102540.

73. Andrade, M.C.; Bolzoni, F.; Fullea, J. Analysis of the relation between water and resistivity isotherms in concrete. Mater. Corros. 2011, 62, 130-138, doi:10.1002/maco.201005777.

74. Martínez-Molina, W.; Torres-Acosta, A.A.; Jáuregui, J.C.; Chávez-García, H.L.; Alonso-Guzmán, E.M.; Graff, M.; Arteaga-Arcos, J.C. Predicting concrete compressive strength and modulus of rupture using different NDT techniques. Adv. Mater. Sci. Eng. 2014, 2014, doi:10.1155/2014/742129.

75. Yildirim, H.; Ilica, T.; Sengul, O. Effect of cement type on the resistance of concrete against chloride penetration. Constr. Build. Mater. 2011, 25, 1282-1288, doi:10.1016/j.conbuildmat.2010.09.023.

76. Nokken, M.; Boddy, A.; Wu, X.; Hooton, R.D. Effects of temperature, chemical, and mineral admixtures on the electrical conductivity of concrete. J. ASTM Int. 2008, 5, doi:10.1520/JAI101296.

77. Bouzoubaâ, N.; Zhang, M.-H.; Malhotra, V.M.; Golden, D.M. Blended fly ash cements-A review. ACI Mater. J. 1999, 96, 641650.

78. Ortega, J.M.; Pastor, J.L.; Albaladejo, A.; Sánchez, I.; Climent, M.A. Durability and compressive strength of blast furnace slagbased cement grout for special geotechnical applications. Mater. Constr. 2014, 64, doi:10.3989/mc.2014.04912.

79. Ortega, J.M.; Tremiño, R.M.; Sánchez, I.; Climent, M.Á. Effects of environment in the microstructure and properties of sustainable mortars with fly ash and slag after a 5-year exposure period. Sustainability2018, 10, 663, doi:10.3390/su10030663.

80. Atiş, C.D. Accelerated carbonation and testing of concrete made with fly ash. Constr. Build. Mater. 2003, 17, 147-152, doi:10.1016/S0950-0618(02)00116-2.

81. Khan, M.I.; Lynsdale, C.J. Strength, permeability, and carbonation of high-performance concrete. Cem. Concr. Res. 2002, 32, 123131, doi:10.1016/S0008-8846(01)00641-X. 